\title{
Investigation of effectiveness of effective area method for assessing undrained capacity of shallow rectangular foundations
}

\author{
X. Feng ${ }^{1}$, S. Gourvenec ${ }^{2}$, M. F. Randolph ${ }^{3}$ and R. Teng ${ }^{4}$
}

Accepted for publication in Journal of Geotechnical and Geoenvironmental Engineering 19 July 2018

\author{
${ }^{1}$ Xiaowei FENG (corresponding author) \\ Centre for Offshore Foundation Systems \\ A node of the ARC Centre of Excellence in Geotechnical Science and Engineering \\ University of Western Australia \\ 35 Stirling Highway, Crawley \\ Perth, WA 6009 \\ Australia \\ Tel: +61 864882473 \\ Email: xiaowei.feng@uwa.edu.au
}

\section{${ }^{2}$ Susan GOURVENEC}

Faculty of Engineering and the Environment

University of Southampton

University Road

Southampton, SO17 1BJ

UK

Tel: +44 02380599139

Email: susan.gourvenec@southampton.ac.uk

\section{${ }^{3}$ Mark F. RANDOLPH}

Centre for Offshore Foundation Systems

A node of the ARC Centre of Excellence in Geotechnical Science and Engineering University of Western Australia

35 Stirling Highway, Crawley

Perth, WA 6009

Australia

Tel: +61 864883075

Email: mark.randolph@uwa.edu.au

\section{${ }^{4}$ Renjie TENG}

Former MPE student, School of Civil, Environmental and Mining Engineering

University of Western Australia

35 Stirling Highway, Crawley

Perth, WA 6009

Australia

Email: 21005105@student.uwa.edu.au

No. of words: 3621 (without abstract and references)

No. of tables: 4

No. of figures: 12 


\section{ABSTRACT}

5 This paper investigates the effectiveness of the effective area method (EAM) for assessing the 6 undrained load-carrying capacity of rectangular foundations under combined vertical (V), 7 horizontal $(H)$ and moment loading $(M)$ by comparing with finite-element method (FEM) bearing capacity; footings/foundations; failure; rafts; clays

\section{Investigation of effectiveness of effective area method for assessing undrained capacity of shallow rectangular foundations}

\author{
X. Feng ${ }^{1}$, S. Gourvenec ${ }^{2}$, M. F. Randolph ${ }^{3}$ and R. Teng ${ }^{4}$
}

results. Predicted ultimate limit states under combined loading from the two methods are compared and the equivalent rectangle derived from the EAM is compared with the contact region obtained from the FEM. For one-way eccentricity, good agreement in the $V$ - $M$ capacity is achieved with the two methods despite differences between the effective area and actual contact area. However, $V-M$ capacity for two-way eccentricity obtained from the EAM is significantly smaller than that derived from the FEM, with the discrepancy becoming more pronounced with increasing mobilisation of the vertical capacity. $V-H-M$ failure envelopes established by the EAM also fall significantly inside those determined using FEM. The contributing factors for the discrepancies are explored systematically in the paper.

\section{KEYWORDS}

19 


\section{INTRODUCTION}

\section{Motivation and scope}

The effective area method (EAM) is widely used to calculate the undrained load-carrying capacity of shallow foundations under combined loading in conjunction with a load inclination factor, and modification factors to account for other boundary conditions including foundation shape and embedment, and soil strength heterogeneity. The effective width method was derived originally for consideration of eccentrically applied vertical loading on strip foundations and has since been applied to other foundation geometries and more complex loading conditions including biaxial moment.

The finite element method (FEM) can be an alternative for routine design. Shen et al. (2016) investigated the undrained load-carrying capacity of strip and circular foundations through FEM under the equivalent boundary conditions to EAM by introducing a zero-tension interface. The predicted capacities by the two methods were compared but the underlying reasons for the differences were not interpreted. In addition, the effectiveness of the EAM for biaxial moment loading could not be considered for the plane strain and circular foundation geometries considered in the study.

This paper investigates the undrained load-carrying capacity obtained from the EAM and FEM for rectangular foundations under combined loading conditions. The objective is to identify and explain discrepancies between the predicted capacities by the two methods by comparing the effective foundation area derived from EAM and the contact region obtained from FEM, and by examining the foundation response and the soil failure mechanism. The effect of the foundation shape on the effectiveness of EAM will also be discussed. The results presented in this note will assist design of shallow foundations where the overturning moment is significant and the tensile resistance of the foundation-soil interface is not reliable. Examples of taking 


$$
V_{d}=F\left(N_{c} s_{u 0}+\frac{\rho B^{\prime}}{4}\right) K_{c} A^{\prime}
$$
(API, 2011)

advantage of the FEM over the EAM for achieving cost-effective design of shallow foundations can be found in Gourvenec, et al. (2017) and Riet, et al. (2017).

\section{Effective area method and traditional bearing capacity theory}

The ‘effective width’ hypothesis was proposed by Meyerhof (1953) for strip foundations to consider the detachment of the foundation due to overturning moment resulting from eccentricity of vertical load. The concept of an 'effective area' has since been developed for other foundation geometries (Hansen, 1961; Taiebat and Carter, 2002). Figure 1 depicts a rectangular foundation subjected to a point load $P$. The eccentric-inclined load $P$ is decomposed into a vertical component $V$ normal to the base and a horizontal component $H$, intersecting the centre of an equivalent fictitious rectangle for which the bearing capacity is calculated. The equivalent rectangle is determined such that the geometrical centre of the rectangle coincides with the point of load application and the rectangle follows as closely as possible the nearest contour of the actual bearing area (Hansen, 1970). The load inclination is included by further reducing the bearing capacity of the rectangle. Then, the load-carrying capacity of a rectangular foundation is defined as the pure vertical capacity of the equivalent rectangle. The maximum vertical load $V_{d}$ that the foundation can support at base level is conventionally expressed as

where $\mathrm{F}$ is a correction factor given as a function of foundation roughness and $\rho B^{\prime} / s_{u 0}$ (Davis \& Booker, 1973), with $\rho$ the gradient of the increase of undrained shear strength with depth, $s_{u} 0$ the undrained shear strength of the soil at foundation level, and $N_{c}$ is the plane strain bearing capacity factor for uniform shear strength $(2+\pi)$. The superposing modification factor $K_{c}$ accounts for load inclination, foundation shape and foundation embedment, according to 


$$
K_{C}=1+s_{C}+d_{c}-i_{C}
$$

66 where $i_{c}$ is the load inclination factor, $s_{c}$ the shape factor and $d_{c}$ the depth factor $\left(d_{c}=0\right.$ in the

67 present study since surface foundations are considered ), expressed as

$$
\begin{aligned}
& i_{c}=0.5-0.5 \sqrt{1-\frac{H}{A^{\prime} s_{u 0}}} \\
& s_{C}=s_{C v}\left(1-2 i_{C}\right)\left(B^{\prime} / L^{\prime}\right)
\end{aligned}
$$

with $A^{\prime}$ the effective area of the foundation, equal to $B^{\prime} L^{\prime} . B^{\prime}$ and $L^{\prime}$ are respectively the minimum and maximum effective lateral foundation dimensions depending on the load eccentricity, i.e.

$$
B^{\prime}=\operatorname{Min}\left(B-2 e_{x}, L-2 e_{y}\right) ; \quad L^{\prime}=\operatorname{Max}\left(B-2 e_{x}, L-2 e_{y}\right)
$$

71 where $e_{x}$ and $e_{y}$ are respectively the eccentricities of the vertical load along the short (B) and

72 long $(L)$ side of the rectangular foundation (see Fig. 1), with

$$
e_{x}=-M_{y} / V ; e_{y}=M_{x} / V
$$

73 and $s_{c v}$ is approximated as a relationship of $\rho B^{\prime} / s_{u 0}$ according to

$$
S_{C V}=0.18-0.155+\left(\rho B^{\prime} / s_{u 0}\right)^{0.5}+0.021 \rho B^{\prime} / s_{u 0}
$$

\section{$74 \quad$ Finite element method}

An eccentric-inclined load $P$ applied to a shallow foundation (Fig. 2) can be taken as a composition of the vertical, horizontal and moment load components $(V-H-M)$ acting at the centre of the foundation. The $V-H-M$ failure envelopes can therefore be employed to assess the ultimate limit states of foundations as an alternative to the traditional bearing capacity theory, as acknowledged by industry guidelines (API, 2011; ISO, 2016). Finite element modelling of the problem of establishing the failure envelopes for rectangular foundations under $\mathrm{V}-\mathrm{H}-\mathrm{M}$ loading is described in this section. 


\section{Material properties and finite-element mesh}

All the finite element analyses were carried out using the software ABAQUS (Dassault Systèmes, 2014), considering a rigid rectangular foundation with a typical breadth-to-length ratio of $B / L=0.5$, and a square foundation $(B / L=1)$ resting on the surface of a soil that deforms under undrained conditions. The soil was represented with a linear elastic perfectly plastic constitutive law obeying the Tresca failure criterion. The undrained soil shear strength $s_{u}$ was assumed to be uniform or increase linearly with depth according to $s_{u}=s_{u 0}+\rho z$. The degree of soil strength heterogeneity is defined as $\kappa=\rho B / s_{u 0}$, ranging from 0 (uniform soil) to 10 . A constant modulus ratio of $E_{u} / s_{u}=1000$ was prescribed, enabling failure loads to be mobilised with relatively small deformation. To avoid numerical difficulties the Poisson's ratio of $v=$ 0.49 was adopted to approximate the constant volume response of soil under undrained conditions. The foundation was modelled as a weightless, rigid body, with the load reference point located at the midpoint at foundation level.

A half-view of the fully three-dimensional FE mesh is presented in Fig. 3, showing the mesh discretisation on the central plane through the midpoint of the foundation. The FE model comprises 50100 eight-node, hybrid brick elements. The location of the mesh boundaries was examined and selected to extend a distance of $3 B$ from the edges of the foundation and $3 B$ beneath the foundation, sufficiently remote that the failure mechanisms were unaffected. Mesh nodes at vertical boundaries were constrained to prevent out-of-plane displacement, while those at the base of the mesh were fully constrained in all three coordinate directions. A relatively fine mesh was generated in the vicinity of the edges of the foundation and immediately below the foundation to capture the failure loads and mechanisms precisely. 
Foundation-soil interface

105 The contact between the foundation and subsoil is prescribed not to sustain tension to mimic

106 the detachment of the foundation, conforming to the assumption in the EAM. The behaviour of

107 the zero-tension interface can be taken as a limiting case of a non-dilative frictional interface

108 with an angle of friction approaching $90^{\circ}$. The Coulomb friction model with a deliberately high

109 coefficient of friction $\tau / \sigma_{n}=\mu=20$ (i.e. an equivalent friction angle of $\varphi=\tan ^{-1} 20, \sim 87.1^{\circ}$ ) was

110 adopted to simulate essentially 'bonded' tangential behaviour of the interface when the normal

111 stress is compressive (Shen, et al., 2016), whereas the 'hard' contact allowing for separation

112 (so zero tensile normal stress) was employed for the normal behaviour. The sensitivity of the

113 numerical results on $\mu$ will be presented later in the Results section. The 'hard' pressure-

114 overclosure relationship in ABAQUS is invoked by default using the linear penalty method for

115 finite-sliding, surface-to-surface contact. The area in contact between the foundation and the

116 subsoil is the region where the contact is closed. The contact is open if the contact pressure

117 reduces to zero and separated surfaces come into contact when the clearance between them

118 reduces to zero.

119 Analysis programme

120 After establishing the geostatic status, a vertical load, defined as a proportion of the ultimate

121 vertical load $V_{u l t}$, was applied to the foundation to achieve the prescribed $V / V_{u l t}$ ratio.

122 Subsequently, the moment and horizontal load were increased simultaneously at a given loading

123 ratio using load-controlled analyses to detect the failure loads. 
124

125

126

127

128

\section{RESULTS}

The results presented in this paper conform to a sign convention with downward vertical load positive, and the positive horizontal load and moment as shown in Fig. 2 (i.e. left-to-right and clockwise). Adhering to the right-hand rule indicates that the clockwise $M_{y}$ relevant to $H_{x}$ along the positive $x$-axis in Fig. 1 is negative. Therefore, the moment component $M_{y}$ following the sign conventions in Fig. 2 is presented as its absolute value $\left|M_{y}\right|$ in the Cartesian system.

In this section, the results derived from the FEM are compared with corresponding results from the EAM for foundations under combined $V$-M loading with one-way and two-way eccentricity, and under combined $V-H-M$ loading. Results for a rectangular foundation with $B / L=0.5$ are presented first, followed by additional examination of a square foundation $(B / L=1)$ to show the influence of varying aspect ratio on the effectiveness of the EAM.

\section{Combined $V-M$ loading: one-way eccentricity}

The $V-M_{y}$ load-carrying capacity corresponds to the bearing capacity of a foundation subjected to an eccentrically applied vertical load with respect to the $x$ - axis, and $V$ - $M_{x}$ to the $y$ - axis - as shown in Fig. 1. The $V-M_{y}$ and $V-M_{x}$ failure envelopes obtained from the FEM and EAM are shown respectively in Fig. 4a and Fig. 5a. The contact areas obtained from FEM for uniform soil have been compared with the effective rectangles in Fig. 4b and Fig. 5b. In both cases, 'a', 'b' and 'c' correspond to vertical load mobilisation $v=V / V_{u l t}=0.25,0.50$ and 0.75 in the $V-M_{y}$ and $V-M_{x}$ loading plane. The comparison of the magnitude of the area of the contact region and the effective rectangle is summarised in Table 1. Predicted moment capacities under $V-M_{y}$ and $V-M_{X}$ from the two methods are very similar despite the actual bearing area obtained from FEM being larger than the effective foundation area for a given vertical load mobilisation. The reason is that the EAM assumes a general failure of the soil beneath the equivalent rectangle under pure vertical load. For combined $V-M_{y}$ loading with the eccentricity with respect to $x$-axis, a 
more slender equivalent rectangle than the footprint is obtained, i.e. $B^{\prime} / L<B / L=0.5$, whereas

149 the aspect ratio of the equivalent rectangle, $B / L$ ', typically falls between 0.5 and 1 for combined $V-M_{x}$ loading. The vertical capacity derived from FEM is under-predicted by the shape factor adopted by EAM for $B / L<0.5$, but it is over-predicted as the aspect ratio exceeds 0.5 and EAM for $V-M_{x}$ loading. Therefore, the load-carrying capacities obtained from EAM are slightly over-predicted by the FEM in the $V$ - $M_{y}$ loading plane, but generally under-predicted in the $V$ - $M_{x}$ loading plane.

Figure 4a and Figure 5a show that the EAM predicts the $V$ - $M$ capacities accurately under planar loading in either the $x$-z or $y$-z planes for homogenous and non-homogeneous soil profiles, with

$158 \kappa=2,5$ and 10 . Table 1 indicates that the discrepancy between the moment capacities is negligible for $\kappa=10$ and vertical load mobilisation $v=V / V_{u l t}=0.25$, 0.50 and 0.75 , i.e. 'd', 'e' and 'f' on Fig. 4a for combined $V-M_{y}$ loading, and Fig. 5a for the $V-M_{x}$ loading. The contact

161 regions obtained from FEM and the equivalent rectangles from EAM are respectively illustrated 162 in Fig. 4c and Fig. 5c.

\section{Combined $V$-M loading: two-way eccentricity}

The biaxial (i.e. $M_{y}-M_{x}$ ) moment capacity for given vertical load mobilisation, is presented as the bearing capacity of a foundation subjected to a vertical load with dual eccentricities with respect to the $x$ and $y$ axes. The $M_{y}-M_{x}$ failure envelopes derived from FEM and EAM for uniform soil are presented in Fig. 6 for varying moment ratios and either homogeneous soil 168 strength $(\kappa=0)$ and different vertical load mobilisation $v$ (Fig. 6a), or $v=0.5$ and different

169 values of heterogeneity ratio $\kappa$ (Fig. 6b). For given vertical load mobilisation, the gap between the FEM and EAM for the case of two-way eccentricity generally decreases with increasing ratio of $M_{x} /\left|M_{y}\right|$. The associated equivalent rectangle derived from EAM and the actual contact

172 area predicted by the FEM are shown in Table 2 for selected load paths of $M_{x} /\left|M_{y}\right|=4$, 2 and 1. 
173 While equivalent rectangles are derived from the EAM under two-way eccentricity, the actual

174 contact regions observed in the FEM are either triangular, trapezoidal or pentagonal (Fig. 7 a

175

176

to d), failing to conform to the criterion that the equivalent rectangle should follow as closely as possible the nearest contour of the effective foundation bearing area (Hansen, 1970). The oblique dash-dot lines shown in Fig. 7 indicate the orientation and the position of the rotation axis, which are determined by plotting the contours of the foundation vertical displacement within an extremely narrow range close to zero at the instant of failure owing to the action of the biaxial moment.

Unlike with one-way eccentricity where the axis of rotation automatically coincides with that of the moment and is orthogonal to the plane of loading, under two-way eccentricity the foundation has a strong tendency to rotate about the long side, for which the moment resistance is smaller. Vectors of rotation obtained from the FEM for biaxial moment loading at $v=0.5$ are shown in Fig. 8 for homogeneous soil ( $\kappa=0)$. Unlike in Fig. 6, the moments $M_{y}$ and $M_{x}$ in Fig. 8 are both normalised by $A B s_{u}$ so that the plastic potential vectors are parallel to the axis about which the foundation rotates. The angle of the axis of rotation from the long side of the foundation is summarised in Table 3 together with the corresponding direction of the resultant moment for $\kappa=0$ and $\mathrm{v}=0.25,0.5$ and 0.75 . The angle of the axis of rotation from the long side for given load path varies within a range of $5^{\circ}$ for varying vertical load mobilisation, and is always smaller than the angle of the resultant moment. However, EAM does not consider the stronger tendency for rotation about the (weaker) long axis, such that the reduction in $M_{y}$ capacity due to the presence of $M_{x}$ is more significant in EAM than in FEM for biaxial moment loading. These factors lead to the discrepancy in the predicted moment capacity by FEM and EAM under two-way eccentricity being more pronounced than under one-way eccentricity, for any given vertical load mobilisation. 
The contact region and the potential of the foundation to rotate about the weak axis are

198 illustrated in Fig. 7d for an example case of $\kappa=10$, for load paths of $M_{\chi} /\left|M_{y}\right|=4,2$ and 1 . The contact shape, in comparison with the contact footprint using the EAM, confirms again the intrinsic conservatism of the EAM in predicting the $V$ - $M$ capacity under two-way eccentricity for different soil strength profiles.

\section{Combined V-H-M loading}

The coefficient of friction $\mu$ adopted in the FEM is of particular importance for the combined $V$ - $H$ - $M$ loading for $v<0.5$ when the sliding failure of the foundation is dominant. The sensitivity on $\mu$ is demonstrated in Fig. 9 by comparing the $H-M$ failure envelopes obtained from FEM for foundation under $v=0.25$, and on a uniform soil. The discrepancy in the load-carrying capacity for any loading paths is negligible if $\mu \geq 5$, ensuring the reliability of the use of $\mu=20$ for the foundation-soil interface.

$H-M$ failure envelopes for planar loading in the $x$-z plane obtained from EAM and FEM are shown in Fig. 10 for $v=0.25,0.5$ and 0.75 for a rectangular foundation with $B / L=0.5$. For a low level of vertical load mobilisation, e.g. $v=0.25$, the maximum mobilised horizontal load

212 equates approximately to the product of the bearing area and the soil strength at foundation 213 level for all loading paths (as summarised in Table 4), indicating that the critical failure mode 214 is governed by sliding across the foundation level for both methods. However, the EAM reduces 215 the bearing area linearly with the mobilised moment until close to bearing failure whilst the 216 reduction derived from the FEM is rather non-linear due to the presence of the horizontal load. 217 At failure point 'a' in Fig. 10a for uniform soil $(\kappa=0)$ and $\left|M_{y}\right| / B H_{x}=0.27$, significant moment 218 ( $\sim 37 \%$ of $M_{u l t}$ ) has been mobilised but the contact between the foundation and the subsoil obtained from FEM is virtually intact, reduced by only 4\% (Table 4). By contrast, the EAM does not capture the true interaction between $H$ and $M$ and simply reduces the intact bearing 
222 load path of $\left|M_{y}\right| / B H_{x}=0.27$, the reduction in contact area for 'b' is $28 \%$. Similar shortfalls

223 exist for the non-homogeneous soil profiles, for instance the available moment resistance at point 'c' for $\kappa=10$ and $\left|M_{y}\right| / B H_{x}=0.57$ on Fig. 10a is approximately $41 \%$ of the ultimate value

with nearly intact contact, whereas the equivalent foundation area for ' $d$ ' derived from the EAM

for same boundary condition as ' $c$ ' is reduced by $28 \%$ of the original. For sliding failure, the

discrepancies in capacity between the two methods is attributed to the EAM reducing the bearing area with the mobilised moment more significantly than FEM by ignoring the true interaction between $H$ and $M$ for all soil strength profiles.

At high vertical load mobilisation, e.g. $v \geq 0.5$, an asymmetry of the $V-H-M$ failure envelopes from FEM becomes evident. This is due to the interaction between $H$ and $M$. When a left-toright horizontal load acts with a clockwise moment (see Fig. 2), soil failure is more localised at the foundation level but a deeper soil scoop is mobilised beneath the foundation if $H$ changes its direction (Fig. 11). The contact area obtained from FEM, shown in Table 4, for $H$ acting in 235 the same direction as $M$, e.g. $\left|M_{y}\right| / B H_{x}=1.00$, is always smaller than that when $H$ was applied 236 in opposition, i.e. $\left|\mathrm{M}_{\mathrm{y}}\right| \mathrm{BH}_{\mathrm{x}}=-1.00$, indicating that the displacement of the soil scoop has a tendency to close the gap between the foundation and soil. These explain the asymmetry in the $H-M$ failure envelope. By contrast, EAM assumes vertical bearing failure of the foundation and

239 hence the response of the foundation is independent of the directions of the coupled $H-M$ 240 loading. Therefore, the failure envelopes derived from EAM are symmetric regardless of the 241 vertical load mobilisation. Ignoring the interaction between $H$ and $M$ explains the divergence 242 for the shape and size of the failure envelopes for all the degrees of soil strength heterogeneity considered.

\section{Effect of variation of foundation aspect ratio}

245 Analyses were also carried out for a square foundation $(B / L=1)$ to assess the effectiveness of 246 the EAM for rectangular foundations of various aspect ratios (Fig. 12). The results of the 
analyses of the square foundation show similar trends as for the foundation with $B / L=0.5$. The

$V-M$ capacity under one-way eccentricity obtained from FEM compares well with the EAM,

whilst the $V-M$ capacity under two-way eccentricity derived from EAM falls well inside the

under $v=0.5$ for $\kappa=0,2,5$ and 10 , indicating that the same findings are relevant for the EAM in interpreting the interaction between $H$ and $M$ for both foundation aspect ratios.

\section{3}

\section{CONCLUDING REMARKS}

254 The load-carrying capacity of rectangular foundations has been investigated using the 255 traditional effective area method (EAM) and the finite-element method (FEM). The configuration and the area of the contact region derived from FEM are compared with that of the equivalent rectangles obtained from the EAM for various load paths. The results have revealed that:

- For combined $V-M$ loading with one-way eccentricity, the configuration of the contact region obtained from FEM is generally rectangular and the capacities derived from EAM and FEM fall within $6.6 \%$ of each other.

- For combined V-M loading with two-way eccentricity, EAM does not consider the stronger potential of the foundation to rotate about the axis of least moment resistance, and the equivalent rectangles derived from EAM are rather different from the contact regions obtained from FEM, leading to significant discrepancy in the predicted capacities. The difference between the predicted moment capacity obtained from EAM and FEM can increase up to $36.4 \%$ as the vertical load mobilisation increases to 0.75 for the biaxial moment loading paths examined. 
- For combined $V-H-M$ loading, the effective area method does not take account of interaction between the horizontal load and moment, so that the size and shape of the $V-H-M$ failure envelopes derived from the EAM are rather different from the FEM.

272

The study has shown that EAM is effective for predicting the $V-M$ capacity for shallow foundations with one-way eccentricity, which is what the method was originally derived for. This is true for all soil strength profiles and foundation aspect ratios, but the EAM is unsuitable for predicting the case of two-way eccentricity - with the exception of circular foundation geometry due to the absence of directionality, e.g. (Shen, et al., 2016). For combined $V-H-M$ loading, the results have indicated that significant load carrying capacity can be overlooked for all foundation geometries and all soil strength heterogeneity factors with the EAM.

The suitability and accuracy of the effective area method has been examined systematically in this paper. Results obtained from finite element analyses have demonstrated quantitatively the increasing conservatism by ignoring the coupling effects among different loading components as the nature of moment loading becomes more biaxial and as the presence of horizontal loading becomes more pronounced.

\section{ACKNOWLEDGEMENT}

This work forms part of the activities of the Centre for Offshore Foundation Systems (COFS), established in 1997 under the Australian Research Council's Special Research Centres Program, and supported as a node of the Australian Research Council's Centre of Excellence for Geotechnical Science and Engineering, and through the Fugro Chair in Geotechnics, the Lloyd's Register Foundation Chair and Centre of Excellence in Offshore Foundations and the Shell EMI Chair in Offshore Engineering. 


\section{REFERENCES}

292

314 Salgado, R., Lyamin, A. V., Sloan, S. W., and Yu, H. S. (2004). "Two- and three-dimensional

API (2011). "Recommended Practice 2GEO Geotechnical and Foundation Design Considerations - $1^{\text {st }}$ Edition." American Petroleum Institute, Washington.

Dassault Systèmes (2014). ABAQUS 6.14 Analysis User's Manual, Simulia Corp, Providence, RI, USA.

Gourvenec, S., Randolph, M. F., and Kingsnorth, O. (2006). "Undrained bearing capacity of square and rectangular footings." Int. J. Geomech., 6(3), 147-157.

Gourvenec, S. M., Feng, X., Randolph, M. F., and White, D. J. "A Toolbox for Optimizing

Geotechnical Design of Subsea Foundations." In Proc., Offshore Technology Conference, OTC, Houston, TX, OTC-27703-MS.

Hansen, J. B. (1961). "A general formula for bearing capacity." The Dan. Geotech. Inst. Bull.(No. 11), 38-46.

Hansen, J. B. (1970). "A revised and extended formula for bearing capacity." The Dan. Geotech. Inst. Bull.(No. 28), 5-11.

ISO (2016). "Petroleum and natural gas industries specific requirements for Offshore Structures

- Part 4: Geotechnical and foundation design considerations - $2^{\text {nd }}$ Eidition." International Organization for Standardization, Geneva.

Meyerhof, G. "The bearing capacity of foundations under eccentric and inclined loads." In Proc., the $3^{\text {rd }}$ Int. Conf. Soil Mechanics and Found. Eng., Organizing Committee, Zurich, Switzerland, 440-445.

Riet, B. A. M. v. d., Yenigul, N. B., Burgers, R., and Pisanò, F. "Evaluation of the Intrinsic Conservatism in the Design Codes for Subsea Mudmats." In Proc., Offshore Technology bearing capacity of foundations in clay." Géotechnique, 54(5), 297-306. 
316 Shen, Z., Feng, X., and Gourvenec, S. (2016). "Undrained capacity of surface foundations with

317 zero-tension interface under planar VHM loading." Comput. Geotech., 73, 47-57.

318 Taiebat, H., and Carter, J. (2002). "Bearing capacity of strip and circular foundations on

319 undrained clay subjected to eccentric loads." Géotechnique, 52(1), 61-64. 
320 Table 1 Comparison between FEM and EAM for the load-carrying capacity and actual

321 bearing area under one-way eccentricity

\begin{tabular}{|c|c|c|c|c|c|c|c|c|c|}
\hline \multirow[t]{2}{*}{ Plane } & \multirow{2}{*}{$\begin{array}{l}\text { Soil } \\
\text { heterogeneity }\end{array}$} & \multirow[t]{2}{*}{ Point } & \multirow[t]{2}{*}{$V / V_{u l t}$} & \multicolumn{3}{|c|}{$\left|M_{y}\right| / A B s_{u 0}, M_{x} / A L s_{u 0}$} & \multicolumn{3}{|c|}{ Bearing area/Footprint area } \\
\hline & & & & FEM & EAM & Difference & FEM & EAM & Difference \\
\hline \multirow[t]{6}{*}{$V-M_{y}$} & \multirow[t]{3}{*}{$\kappa=0$} & $\mathrm{a}$ & 0.25 & 0.53 & 0.52 & $2.4 \%$ & 0.34 & 0.27 & $21.8 \%$ \\
\hline & & b & 0.50 & 0.69 & 0.68 & $2.2 \%$ & 0.66 & 0.52 & $20.8 \%$ \\
\hline & & C & 0.75 & 0.53 & 0.50 & $6.6 \%$ & 0.84 & 0.76 & $10.8 \%$ \\
\hline & \multirow[t]{3}{*}{$\kappa=10$} & $\mathrm{~d}$ & 0.25 & 1.03 & 0.99 & $3.8 \%$ & 0.44 & 0.35 & $27.8 \%$ \\
\hline & & e & 0.50 & 1.30 & 1.24 & $5.1 \%$ & 0.66 & 0.59 & $10.9 \%$ \\
\hline & & $\mathrm{f}$ & 0.75 & 0.90 & 0.88 & $2.5 \%$ & 0.85 & 0.81 & $4.8 \%$ \\
\hline \multirow[t]{6}{*}{$V-M_{x}$} & \multirow[t]{3}{*}{$\kappa=0$} & $\mathrm{a}$ & 0.25 & 0.53 & 0.53 & $0.2 \%$ & 0.27 & 0.25 & $9.5 \%$ \\
\hline & & $\mathrm{b}$ & 0.50 & 0.74 & 0.75 & $-1.5 \%$ & 0.54 & 0.47 & $14.9 \%$ \\
\hline & & C & 0.75 & 0.57 & 0.57 & $0.0 \%$ & 0.81 & 0.73 & $11.7 \%$ \\
\hline & \multirow[t]{3}{*}{$\kappa=10$} & $\mathrm{~d}$ & 0.25 & 1.09 & 1.06 & $2.6 \%$ & 0.33 & 0.30 & $8.6 \%$ \\
\hline & & e & 0.50 & 1.42 & 1.44 & $-1.0 \%$ & 0.61 & 0.53 & $16.1 \%$ \\
\hline & & $\mathrm{f}$ & 0.75 & 1.06 & 1.08 & $-2.0 \%$ & 0.81 & 0.76 & $5.8 \%$ \\
\hline
\end{tabular}

Table 2 Comparison between FEM and EAM for the load-carrying capacity and bearing area

\begin{tabular}{|c|c|c|c|c|c|c|c|c|}
\hline \multirow{2}{*}{$\begin{array}{l}\text { Soil } \\
\text { heterogeneity }\end{array}$} & \multirow[t]{2}{*}{$V / V_{\text {ult }}$} & \multirow{2}{*}{$\begin{array}{l}e_{y} / e_{x} \\
\left(M_{x} /\left|M_{y}\right|\right)\end{array}$} & \multicolumn{3}{|c|}{$\left|M_{y}\right| / A B s_{u 0}$} & \multicolumn{3}{|c|}{ Bearing area/Footprint area } \\
\hline & & & FEA & EAM & Difference & FEM & EAM & Difference \\
\hline \multirow[t]{9}{*}{$\kappa=0$} & \multirow[t]{3}{*}{0.25} & 4 & 0.237 & 0.231 & $2.6 \%$ & 0.282 & 0.232 & $21.6 \%$ \\
\hline & & 2 & 0.376 & 0.353 & $6.5 \%$ & 0.292 & 0.250 & $16.8 \%$ \\
\hline & & 1 & 0.475 & 0.439 & $8.2 \%$ & 0.288 & 0.260 & $10.8 \%$ \\
\hline & \multirow[t]{3}{*}{0.5} & 4 & 0.310 & 0.278 & $11.5 \%$ & 0.552 & 0.487 & $13.3 \%$ \\
\hline & & 2 & 0.478 & 0.413 & $15.7 \%$ & 0.571 & 0.500 & $14.2 \%$ \\
\hline & & 1 & 0.615 & 0.526 & $16.9 \%$ & 0.571 & 0.510 & $12.0 \%$ \\
\hline & \multirow[t]{3}{*}{0.75} & 4 & 0.249 & 0.193 & $29.0 \%$ & 0.806 & 0.743 & $8.5 \%$ \\
\hline & & 2 & 0.386 & 0.283 & $36.4 \%$ & 0.817 & 0.750 & $8.9 \%$ \\
\hline & & 1 & 0.484 & 0.365 & $32.6 \%$ & 0.831 & 0.756 & $9.9 \%$ \\
\hline \multirow[t]{3}{*}{$\kappa=10$} & \multirow[t]{3}{*}{0.5} & 4 & 0.600 & 0.520 & $15.4 \%$ & 0.596 & 0.544 & $9.6 \%$ \\
\hline & & 2 & 0.906 & 0.768 & $18.0 \%$ & 0.634 & 0.557 & $13.8 \%$ \\
\hline & & 1 & 1.119 & 0.971 & $15.2 \%$ & 0.654 & 0.571 & $14.6 \%$ \\
\hline
\end{tabular}


Table 3 Angles of the axis of rotation for the foundation under two-way eccentricity derived \\ from FEM}

\begin{tabular}{|l|r|r|r|}
\hline$V / V_{\text {ult }}$ & $\begin{array}{l}e_{y} / e_{x} \\
\left(M_{x} /\left|M_{y}\right|\right)\end{array}$ & $\begin{array}{l}\text { Direction of resultant } \\
\text { moment, } \theta_{M}=\tan ^{-1}\left(M_{x} /\left|M_{y}\right|\right)\end{array}$ & $\begin{array}{c}\text { Angle of axis of rotation } \\
\text { from the long side }(\omega)\end{array}$ \\
\hline 0.25 & 8 & $83^{\circ}$ & $63^{\circ}$ \\
\cline { 2 - 4 } & 4 & $76^{\circ}$ & $46^{\circ}$ \\
\cline { 2 - 4 } & 2 & $63^{\circ}$ & $28^{\circ}$ \\
\cline { 2 - 4 } & 1 & $45^{\circ}$ & $15^{\circ}$ \\
\cline { 2 - 4 } & 0.5 & $27^{\circ}$ & $59^{\circ}$ \\
\hline 0.5 & 8 & $83^{\circ}$ & $42^{\circ}$ \\
\cline { 2 - 4 } & 4 & $76^{\circ}$ & $29^{\circ}$ \\
\cline { 2 - 4 } & 2 & $63^{\circ}$ & $17^{\circ}$ \\
\cline { 2 - 4 } & 1 & $45^{\circ}$ & $10^{\circ}$ \\
\hline 0.75 & 0.5 & $27^{\circ}$ & $63^{\circ}$ \\
\cline { 2 - 4 } & 8 & $83^{\circ}$ & $47^{\circ}$ \\
\cline { 2 - 4 } & 4 & $76^{\circ}$ & $29^{\circ}$ \\
\cline { 2 - 4 } & 2 & $63^{\circ}$ & $15^{\circ}$ \\
\cline { 2 - 4 } & 1 & $45^{\circ}$ & $8^{\circ}$ \\
\hline
\end{tabular}

Table 4 Comparison between FEM and EAM for the load-carrying capacity and actual

334 bearing area under in-plane $V-H-M$ loading

\begin{tabular}{|c|c|c|c|c|c|c|c|c|}
\hline \multirow{2}{*}{$\begin{array}{l}\text { Soil } \\
\text { heterogeneity }\end{array}$} & \multirow[t]{2}{*}{$V / V_{u l t}$} & \multirow{2}{*}{$\begin{array}{l}\text { Load path } \\
\left|M_{y}\right| /\left(B H_{x}\right)\end{array}$} & \multicolumn{3}{|c|}{$\mathrm{H}_{\mathrm{x}} / \mathrm{As}_{\mathrm{u} 0}$} & \multicolumn{3}{|c|}{ Bearing area/Footprint area } \\
\hline & & & FEA & EAM & Difference & FEM & EAM & Difference \\
\hline \multirow[t]{13}{*}{$\kappa=0$} & \multirow[t]{5}{*}{0.25} & 0.13 & 1.02 & 0.84 & $21.4 \%$ & 1.00 & 0.84 & $19.0 \%$ \\
\hline & & 0.27 & 0.97 & 0.72 & $34.7 \%$ & 0.96 & 0.72 & $33.3 \%$ \\
\hline & & 0.57 & 0.67 & 0.55 & $21.8 \%$ & 0.67 & 0.55 & $21.8 \%$ \\
\hline & & 1.00 & 0.45 & 0.40 & $12.5 \%$ & 0.48 & 0.43 & $11.6 \%$ \\
\hline & & -1.00 & -0.45 & -0.40 & $12.5 \%$ & 0.50 & 0.43 & $16.3 \%$ \\
\hline & \multirow[t]{4}{*}{0.5} & 0.13 & 1.00 & 0.89 & $12.4 \%$ & 1.00 & 0.92 & $8.7 \%$ \\
\hline & & 0.27 & 0.94 & 0.80 & $7.5 \%$ & 0.98 & 0.85 & $15.3 \%$ \\
\hline & & 1.00 & 0.54 & 0.46 & $17.4 \%$ & 0.76 & 0.75 & $1.3 \%$ \\
\hline & & -1.00 & -0.57 & -0.46 & $23.9 \%$ & 0.83 & 0.75 & $10.7 \%$ \\
\hline & \multirow[t]{4}{*}{0.75} & 0.13 & 0.79 & 0.62 & $27.4 \%$ & 1.00 & 0.96 & $4.2 \%$ \\
\hline & & 0.27 & 0.74 & 0.54 & $37.0 \%$ & 1.00 & 0.93 & $7.5 \%$ \\
\hline & & 1.00 & 0.41 & 0.31 & $32.2 \%$ & 0.93 & 0.85 & $9.4 \%$ \\
\hline & & -1.00 & -0.45 & -0.31 & $45.2 \%$ & 0.96 & 0.85 & $12.9 \%$ \\
\hline \multirow[t]{2}{*}{$\kappa=10$} & \multirow[t]{2}{*}{0.5} & 1.00 & 0.75 & 0.67 & $11.2 \%$ & 0.92 & 0.73 & $26.1 \%$ \\
\hline & & -1.00 & -0.92 & -0.67 & $37.3 \%$ & 0.95 & 0.73 & $30.1 \%$ \\
\hline
\end{tabular}




\section{FIGURE CAPTIONS}

338 Fig. 1. Schematic of an eccentric-inclined point load applied to a rectangular foundation and

339 the concept of effective foundation area

340 Fig. 2. Load equivalent transformation

341 Fig. 3. FE mesh

342 Fig. 4. Comparison of FEM and EAM for one-way eccentricity with respect to $x$-axis, $V$ - $M_{y}$

343 Fig. 5. Comparison of FEM and EAM for one-way eccentricity with respect to $y$-axis, $V$ - $M_{x}$

344 Fig. 6. Comparison of $M_{y}-M_{x}$ failure envelopes obtained from FEM and EAM

345 Fig. 7. Equivalent rectangle derived from EAM and FE results of contact region, axis of 346 rotation for two-way eccentricity

347 Fig. 8. Example showing the loading direction and vector of rotation

348 Fig. 9. Sensitivity of numerical results on the coefficient of interface friction

349 Fig. 10. Failure envelopes for combined $V-H_{x}-M_{y}$ loading

350 Fig. 11. Example of equivalent plastic strain in the soil for given load path $(v=0.5 ; \kappa=0)$

351 Fig. 12. Effectiveness of the EAM for square foundations and varying soil heterogeneity 


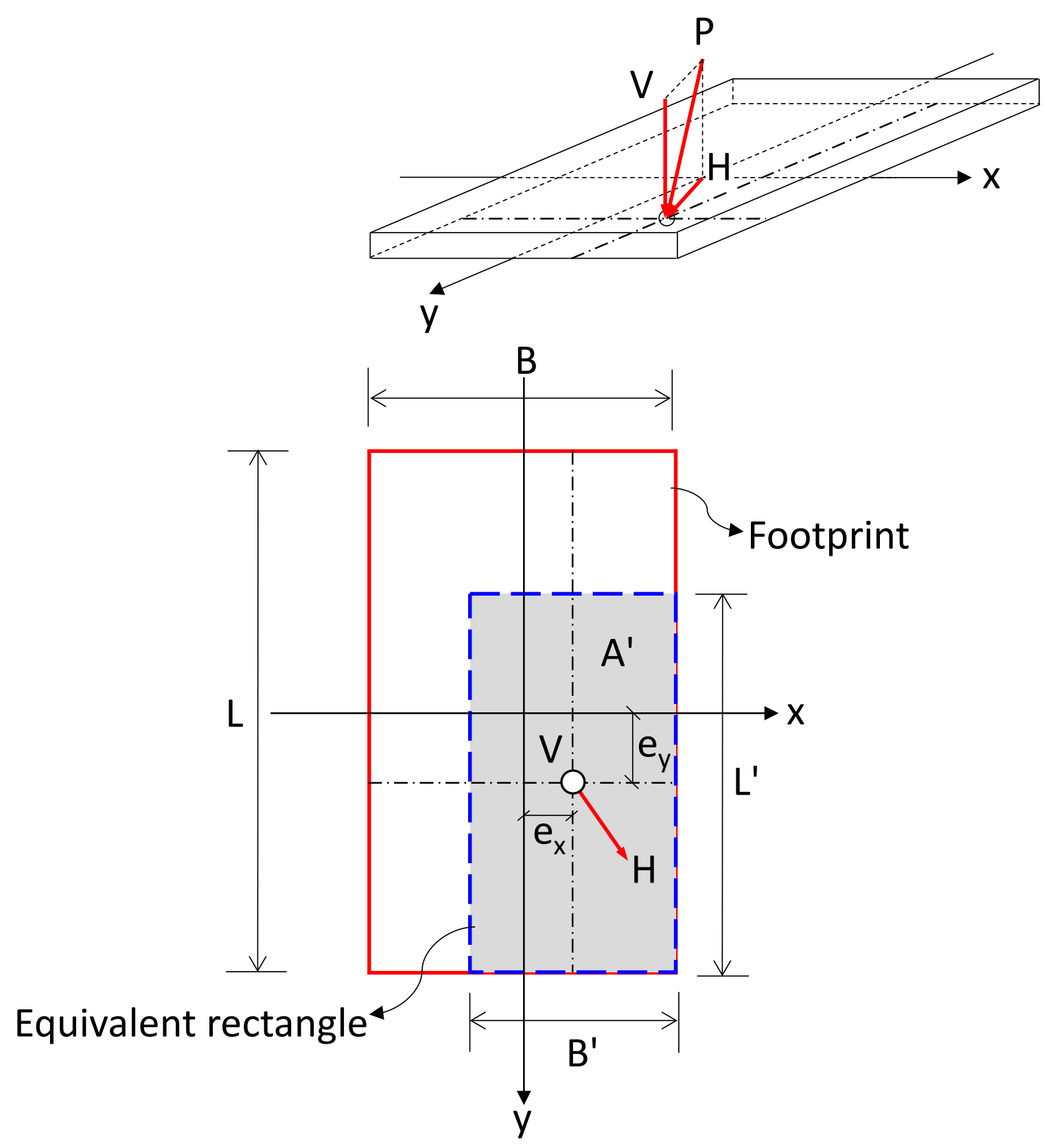

354

355 Fig. 1. Schematic of an eccentric-inclined point load applied to a rectangular foundation and 356 the concept of effective foundation area 


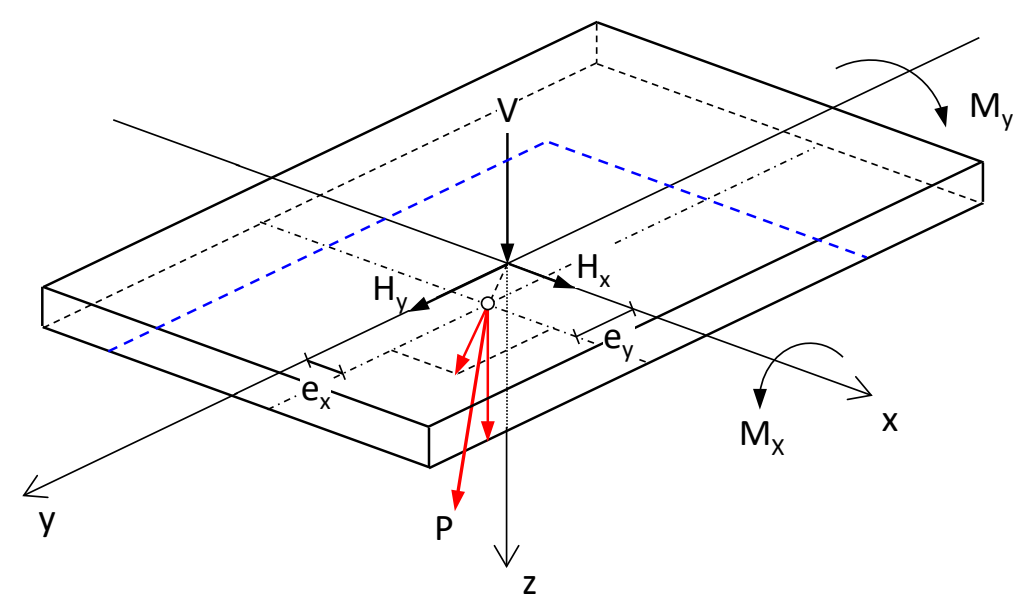

360 Fig. 2. Load equivalent transformation

361

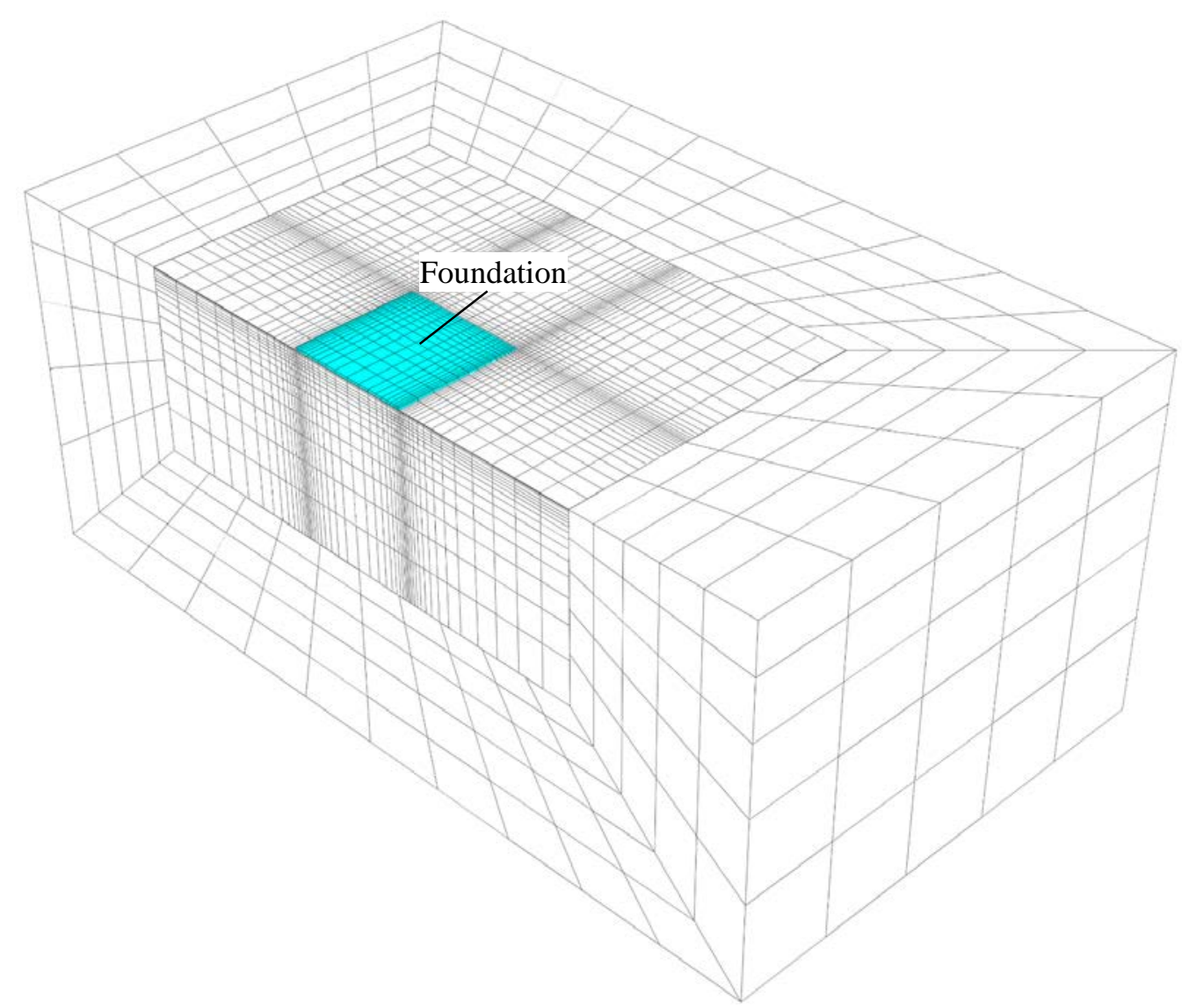

363 Fig. 3. FE mesh 


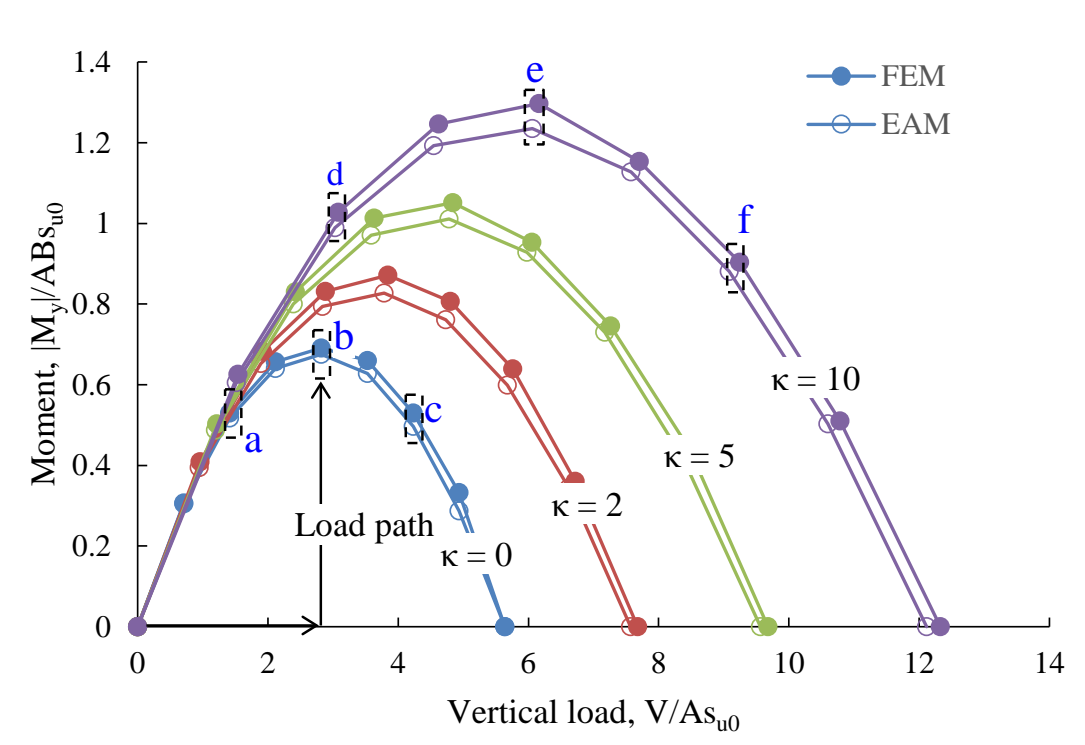

364

365 a) load-carrying capacity
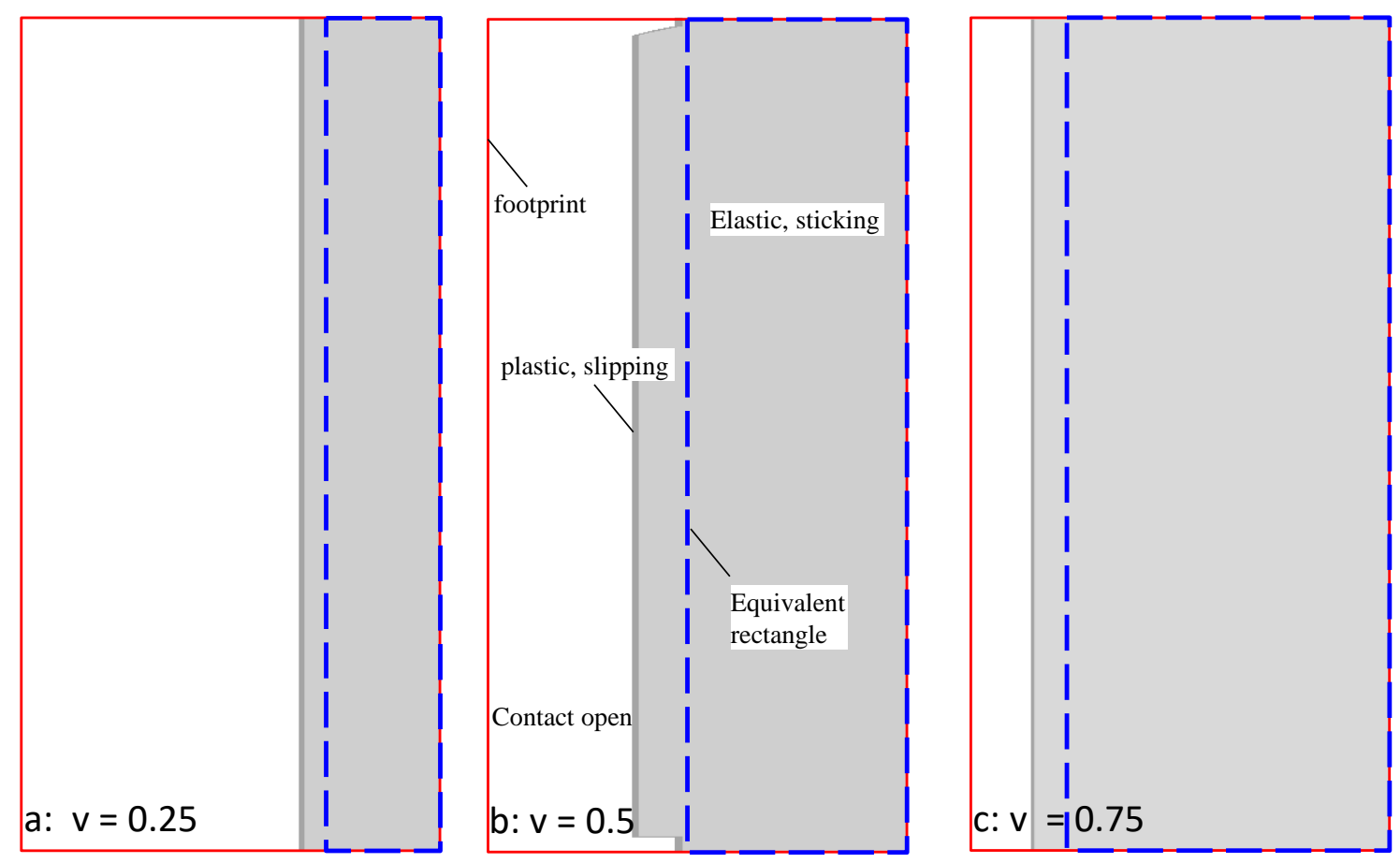

367 b) equivalent rectangle and the contact region: $\kappa=0$ (contact is shown by shaded region) 

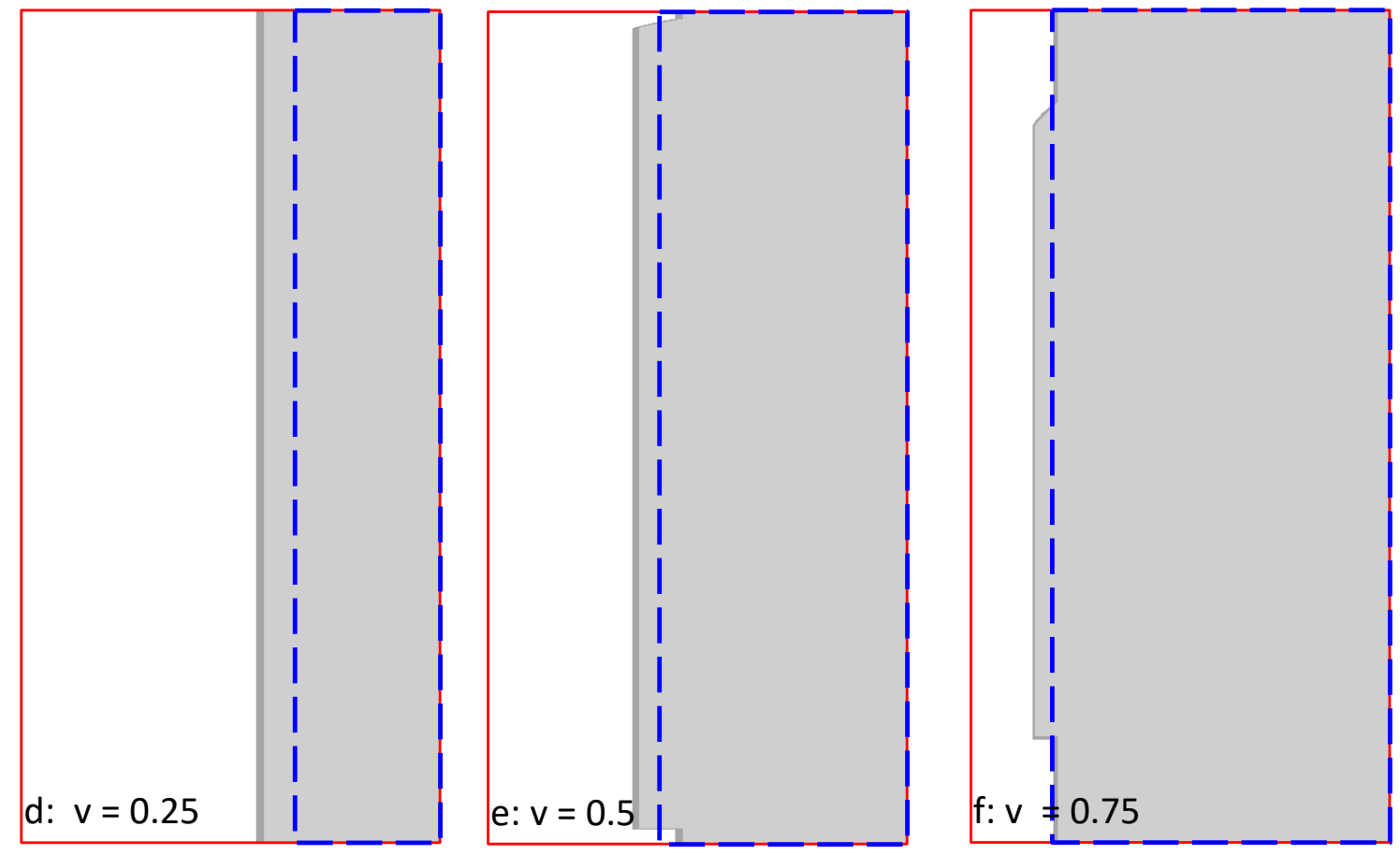

c) equivalent rectangle and the contact region: $\kappa=10$ (contact is shown by shaded region)

Fig. 4. Comparison of FEM and EAM for one-way eccentricity with respect to $x$-axis, $V$ - $M_{y}$

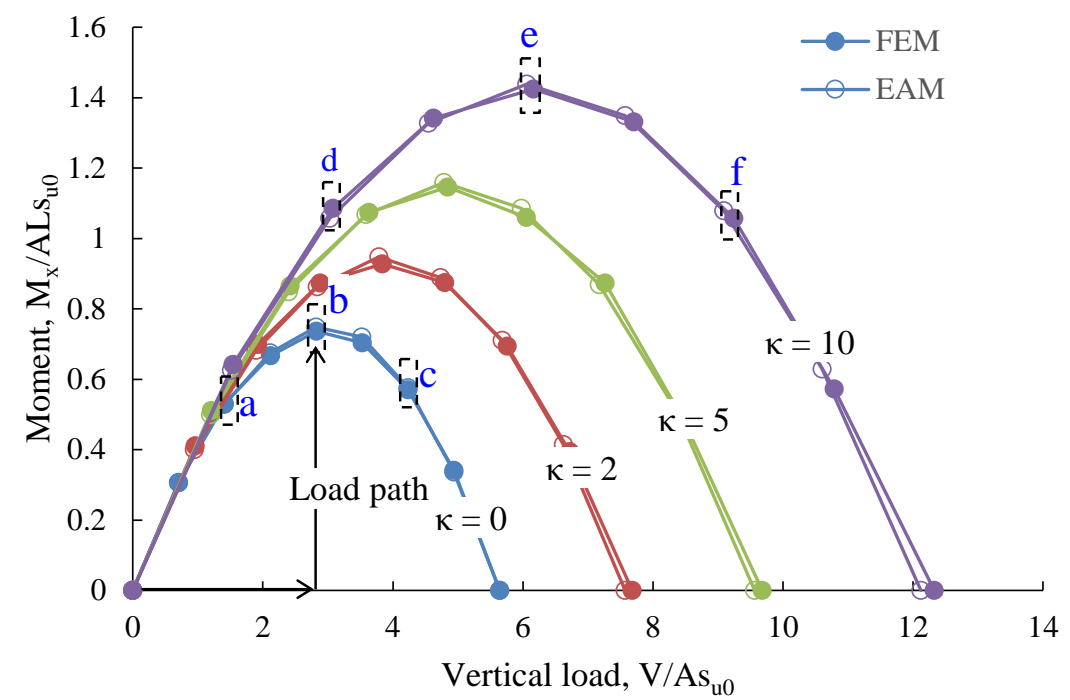

a) load-carrying capacity 

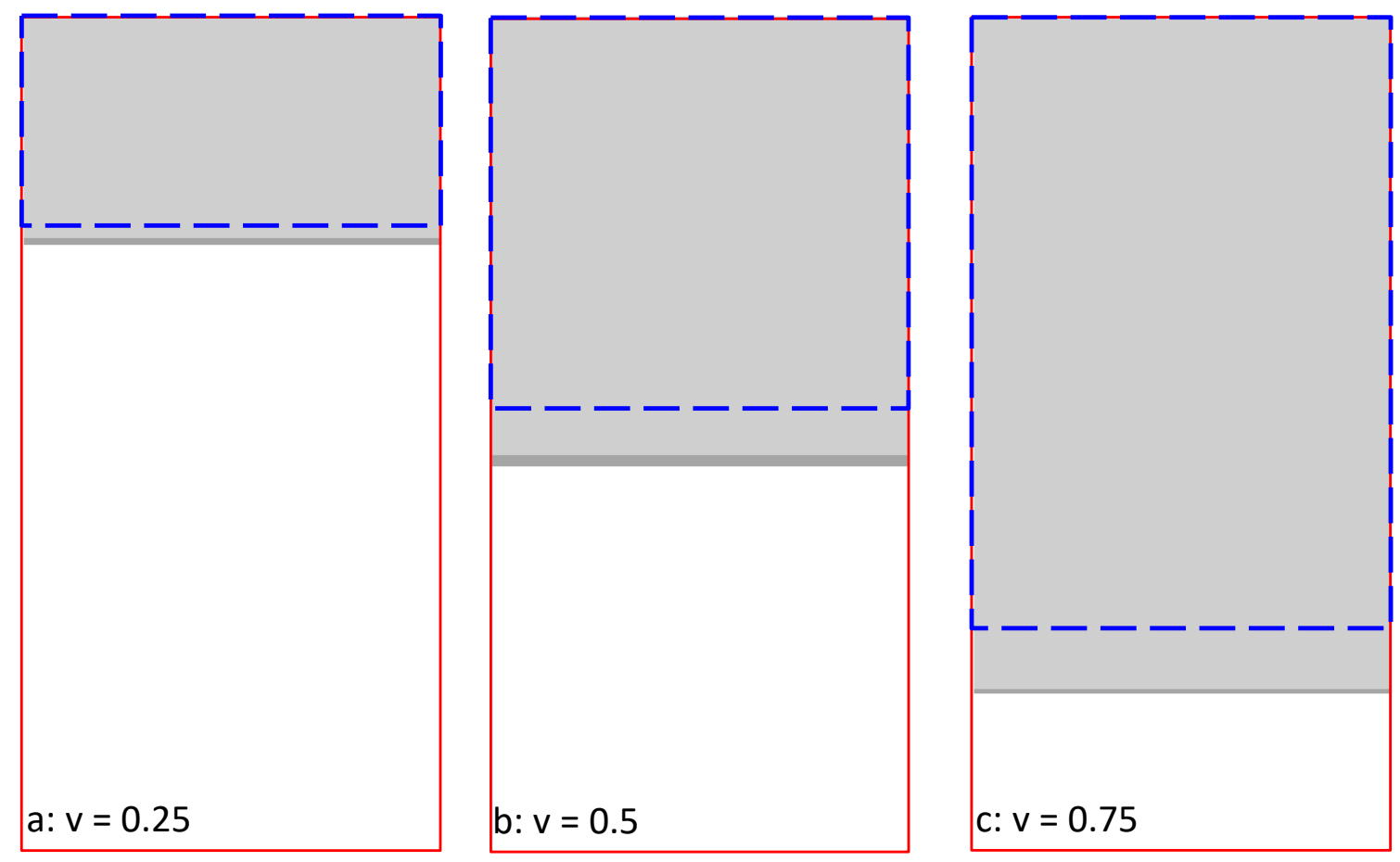

374 b) equivalent rectangle and the contact region: $\kappa=0$ (contact is shown by shaded region)
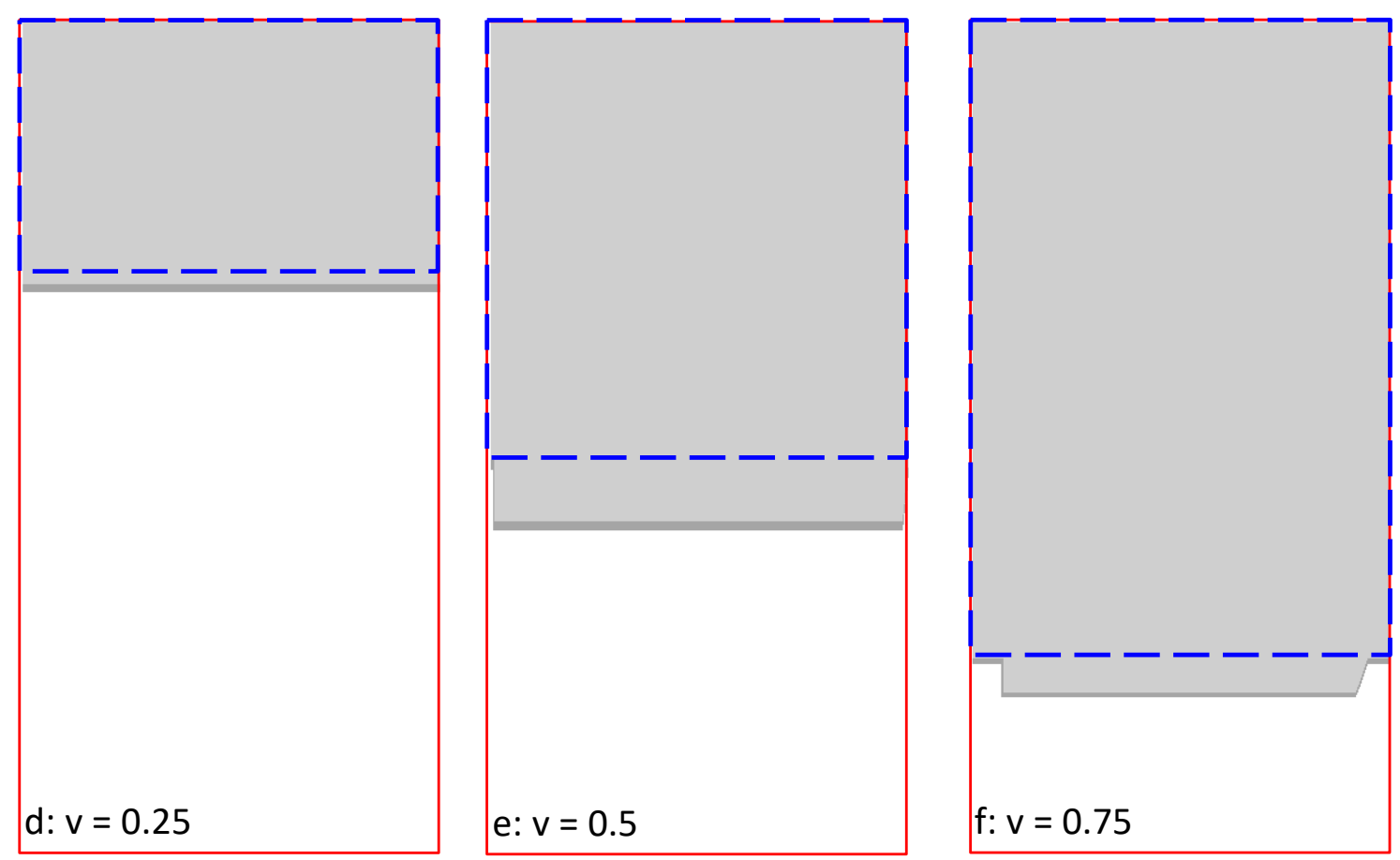
c) equivalent rectangle and the contact region: $\kappa=10$ (contact is shown by shaded region)

Fig. 5. Comparison of FEM and EAM for one-way eccentricity with respect to $y$-axis, $V$ - $M_{x}$

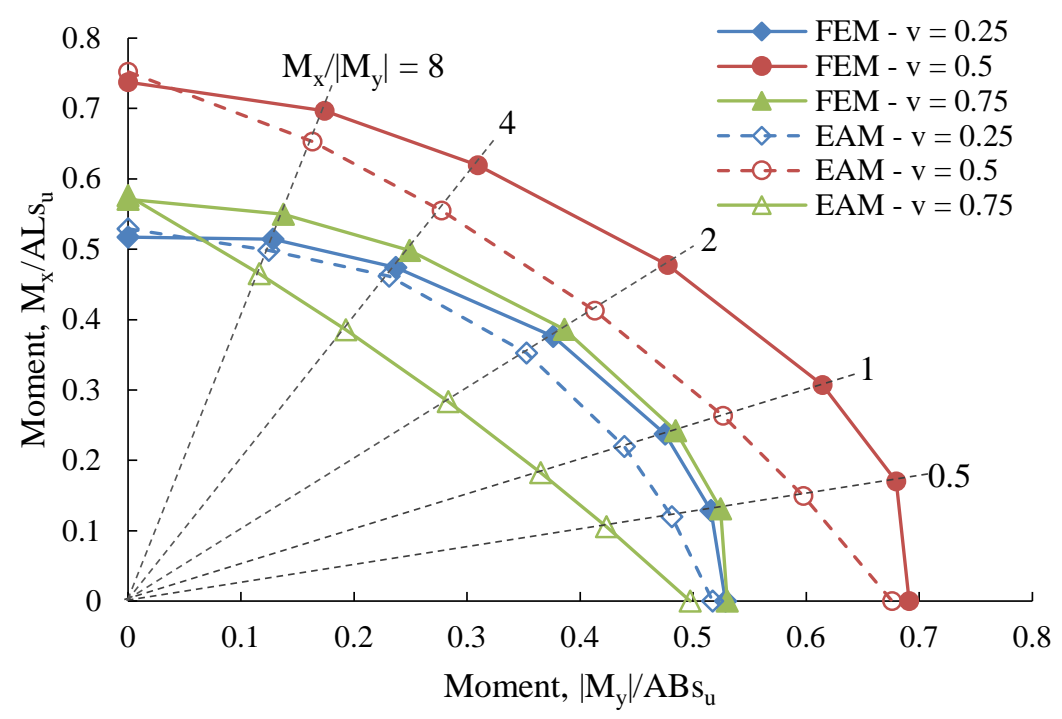

379 a) Biaxial moment capacity for $\kappa=0$ at different vertical load mobilisation

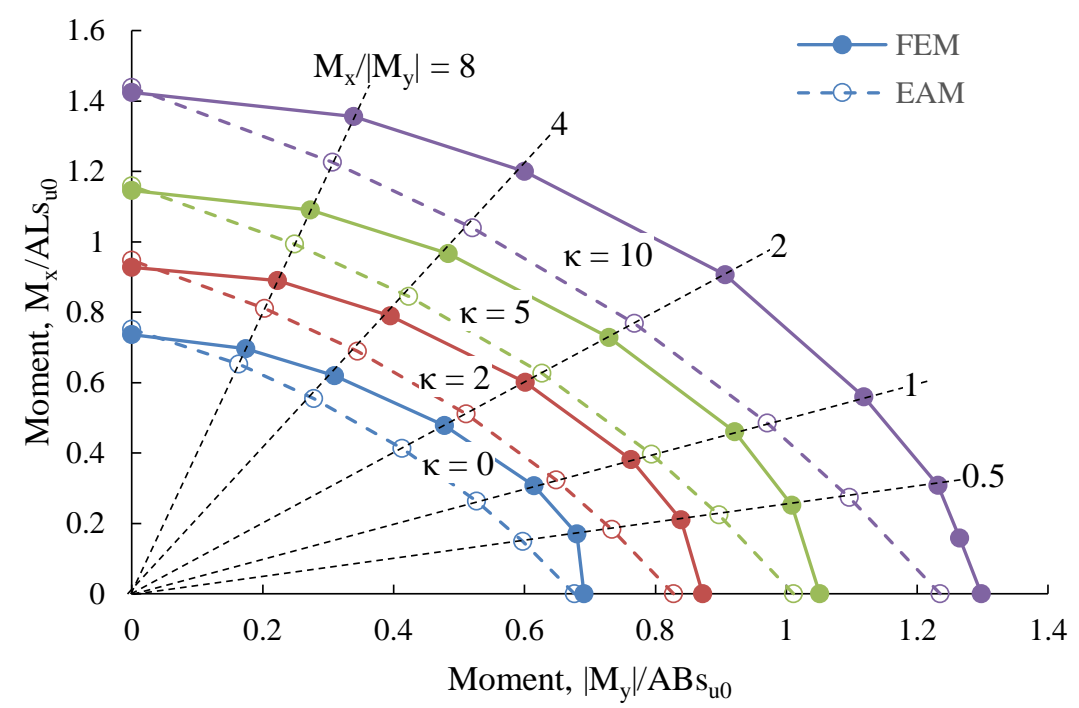

382 b) Biaxial moment capacity at a vertical load mobilisation $\mathrm{v}=0.5$ for different soil strength 383 heterogeneity

384 Fig. 6. Comparison of $M_{y}-M_{x}$ failure envelopes obtained from FEM and EAM 

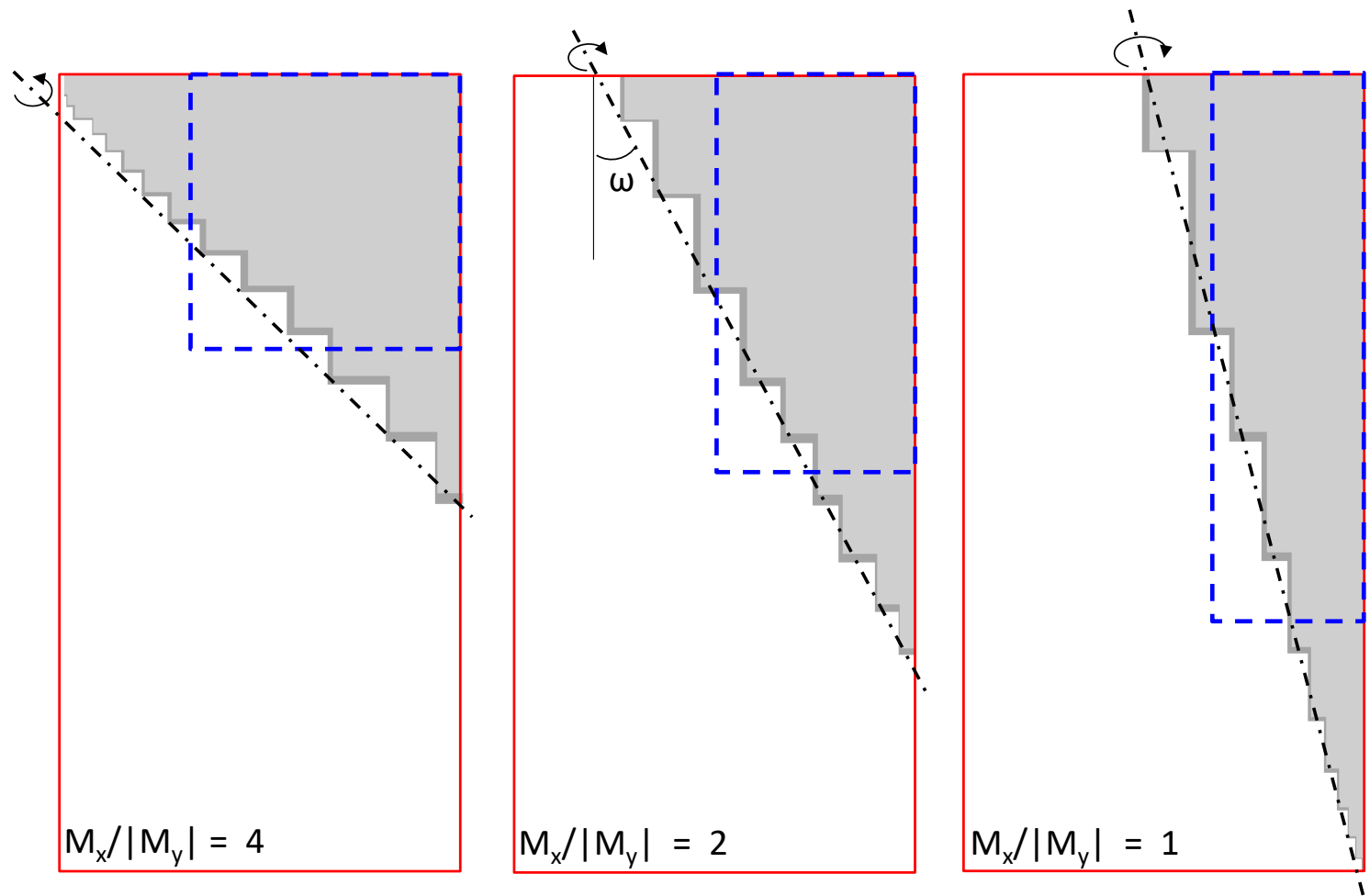

386

a) $\kappa=0 ; v=0.25$

388
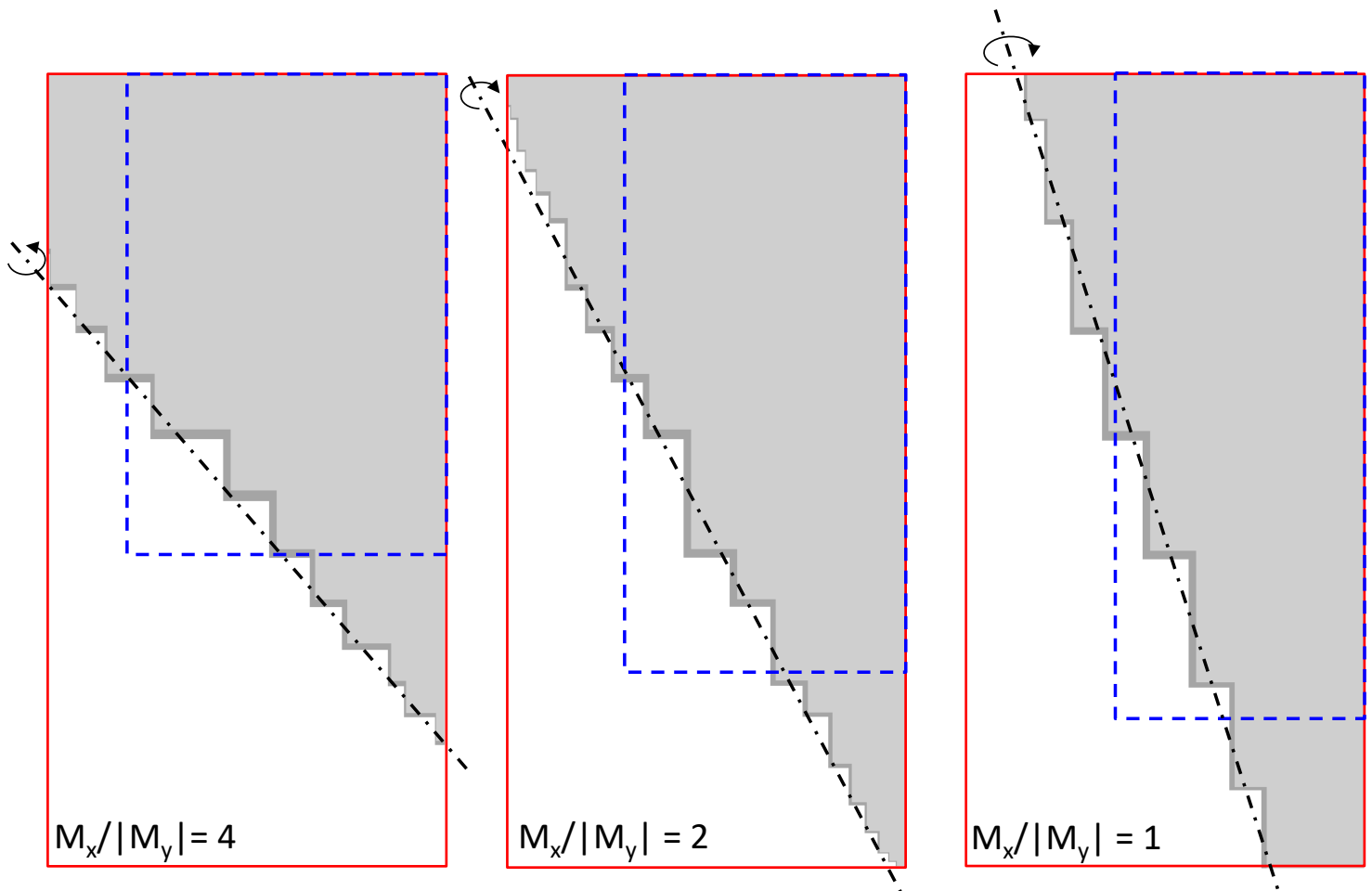
b) $\kappa=0 ; v=0.5$
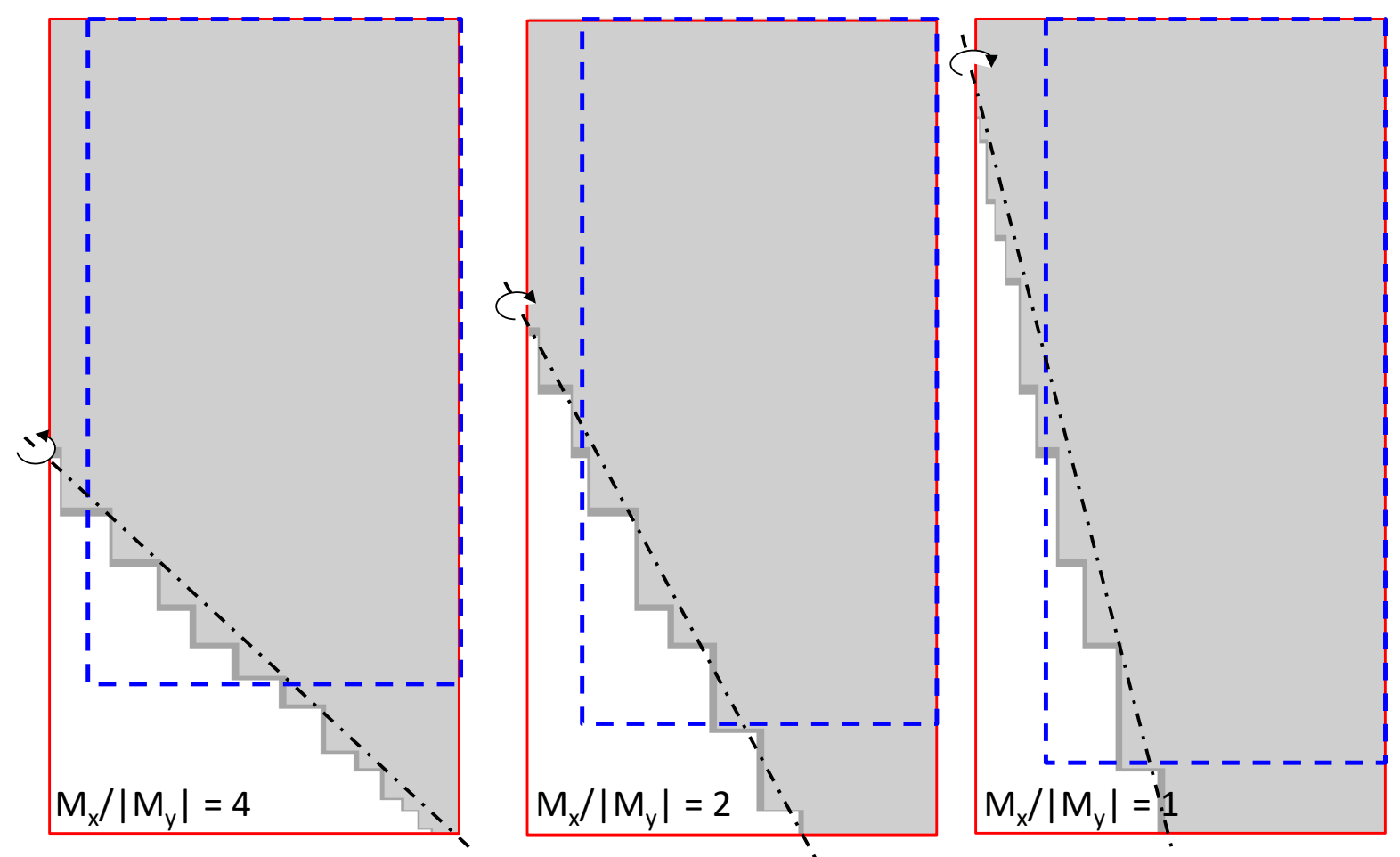

c) $\kappa=0 ; v=0.75$ 

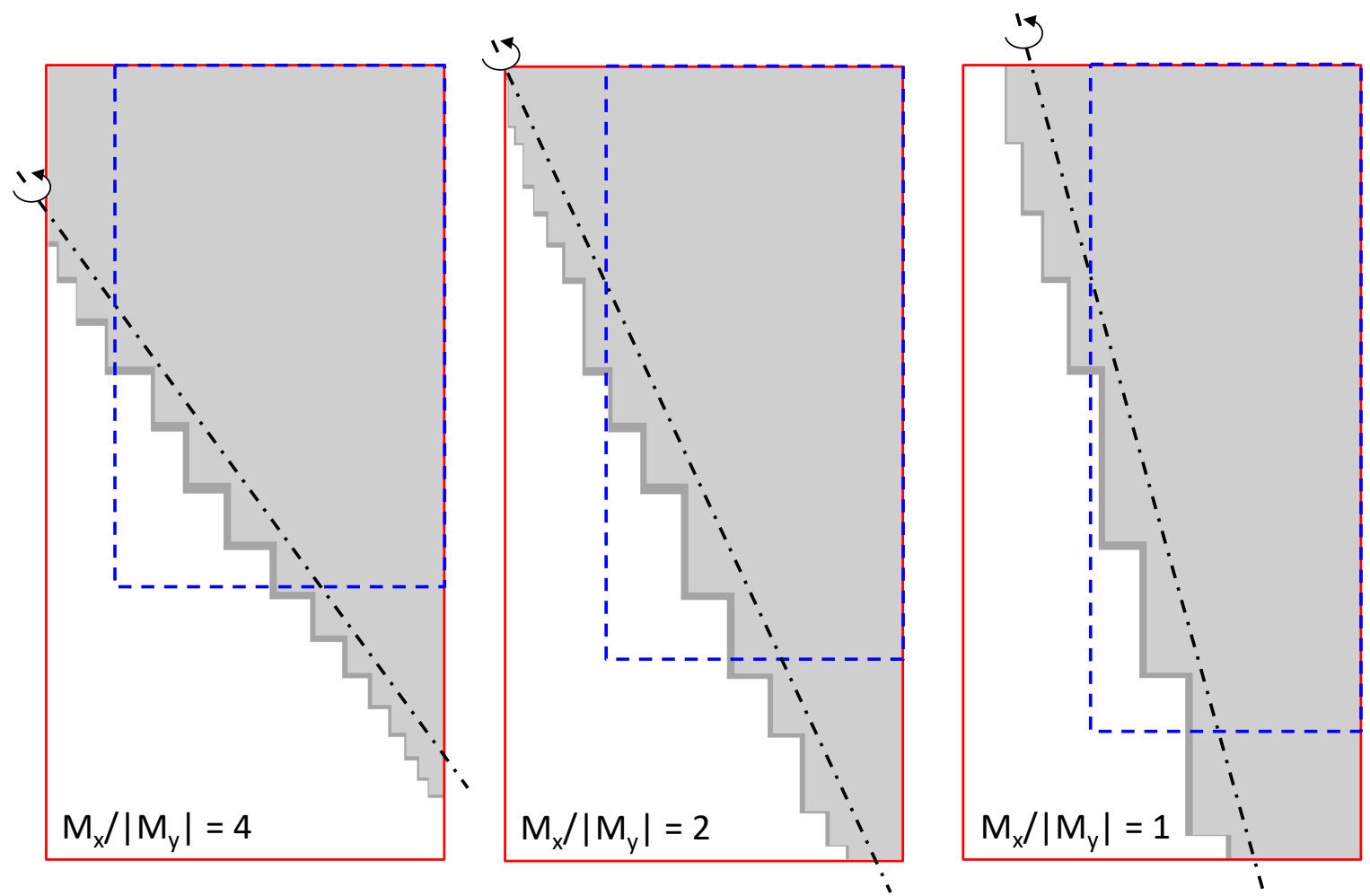

d) $\kappa=10 ; v=0.5$

Fig. 7. Equivalent rectangle derived from EAM and FE results of contact region, axis of rotation for two-way eccentricity

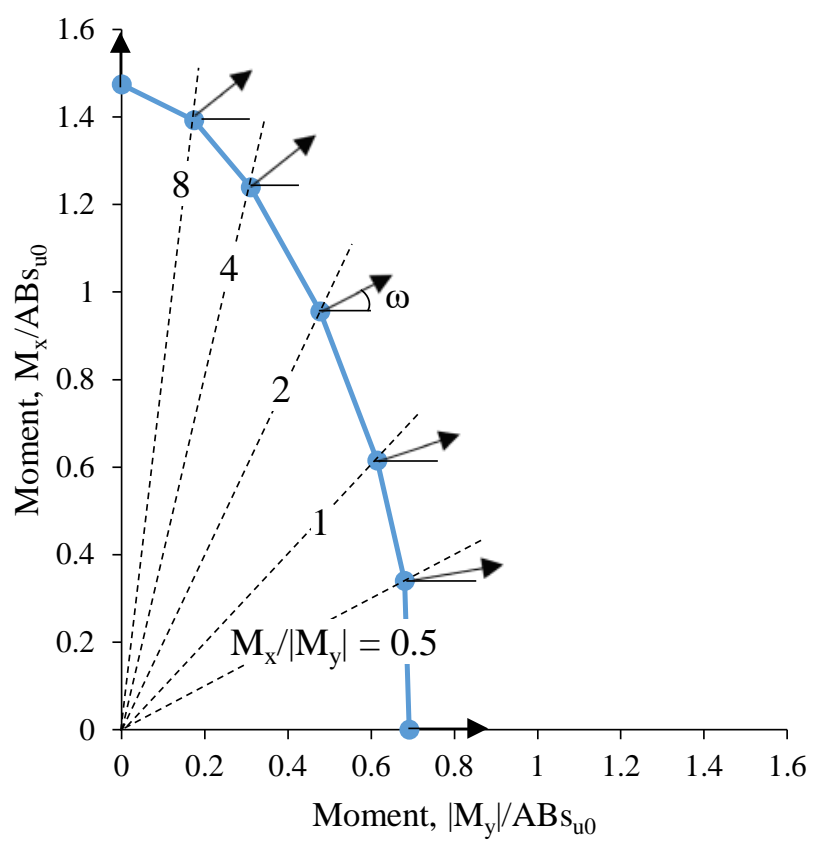

398 Fig. 8. Example showing the loading direction and vector of rotation 


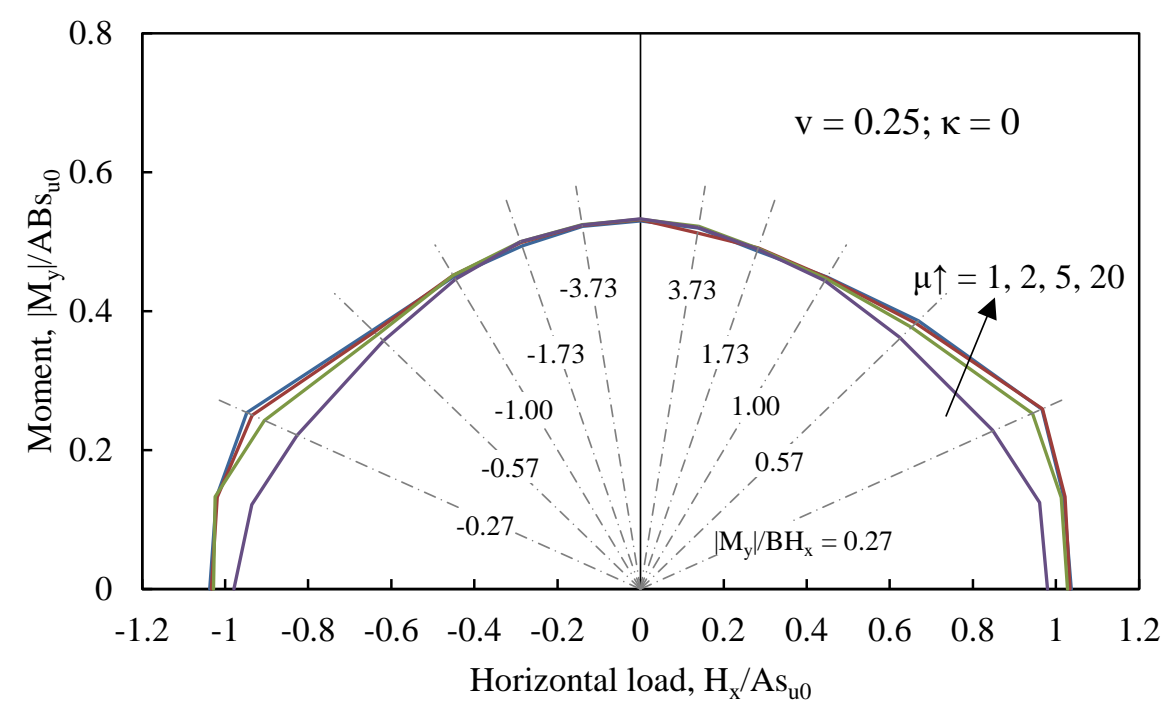

399

400 Fig. 9. Sensitivity of numerical results on the coefficient of interface friction

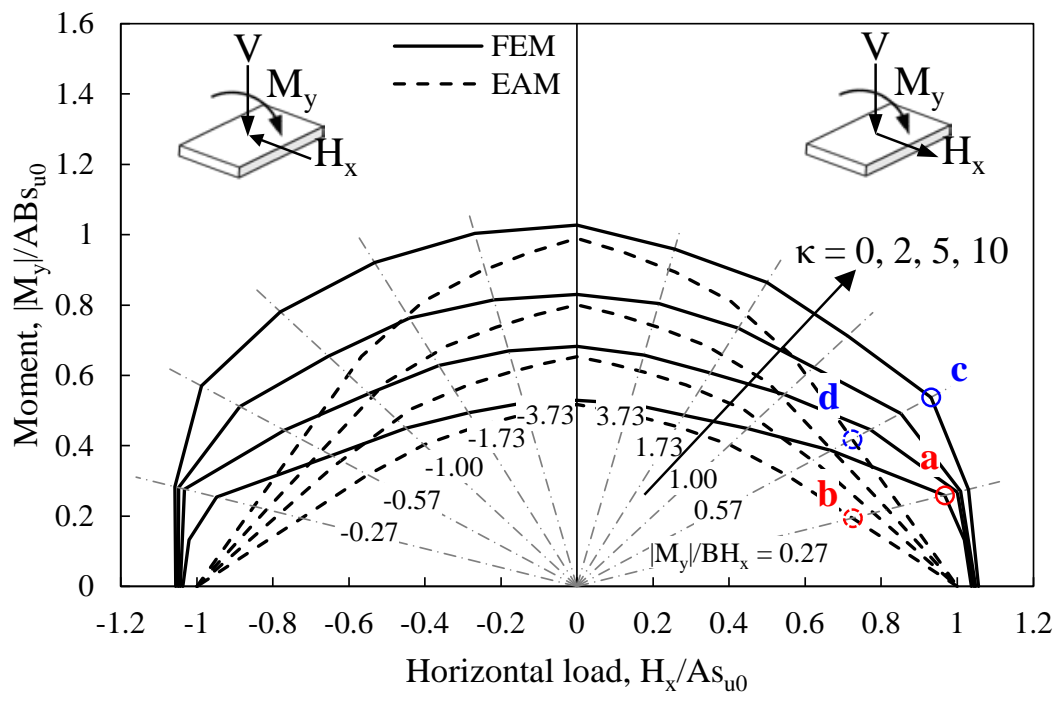

401

402 a) $\mathrm{v}=0.25$ 


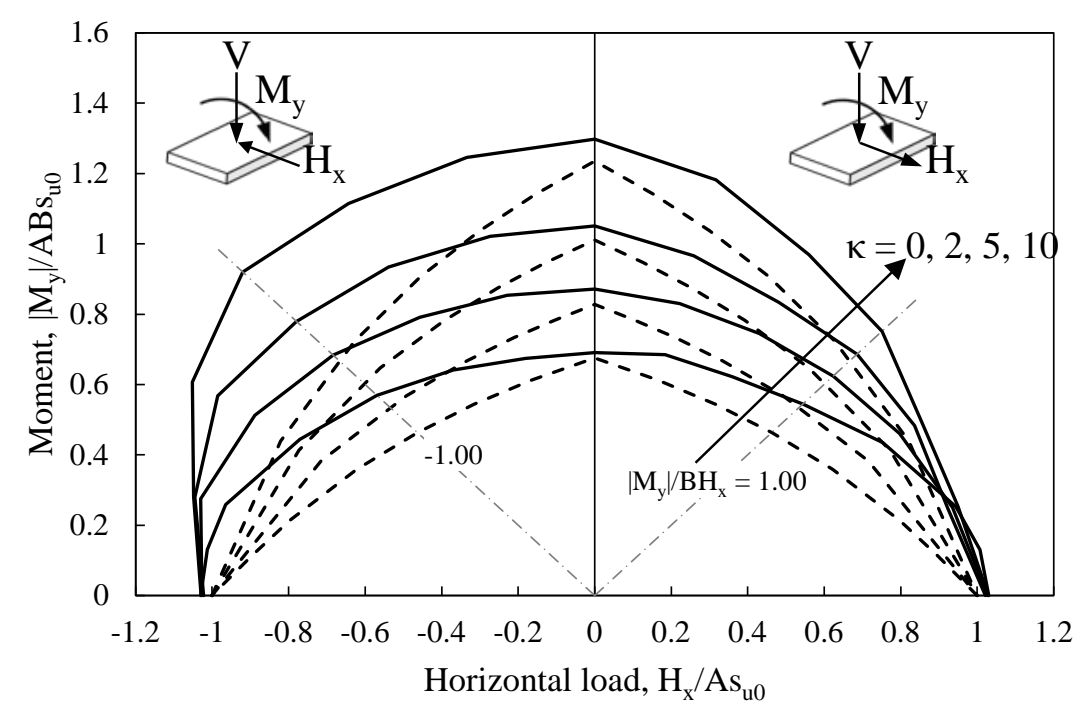

403

404

b) $\mathrm{v}=0.50$

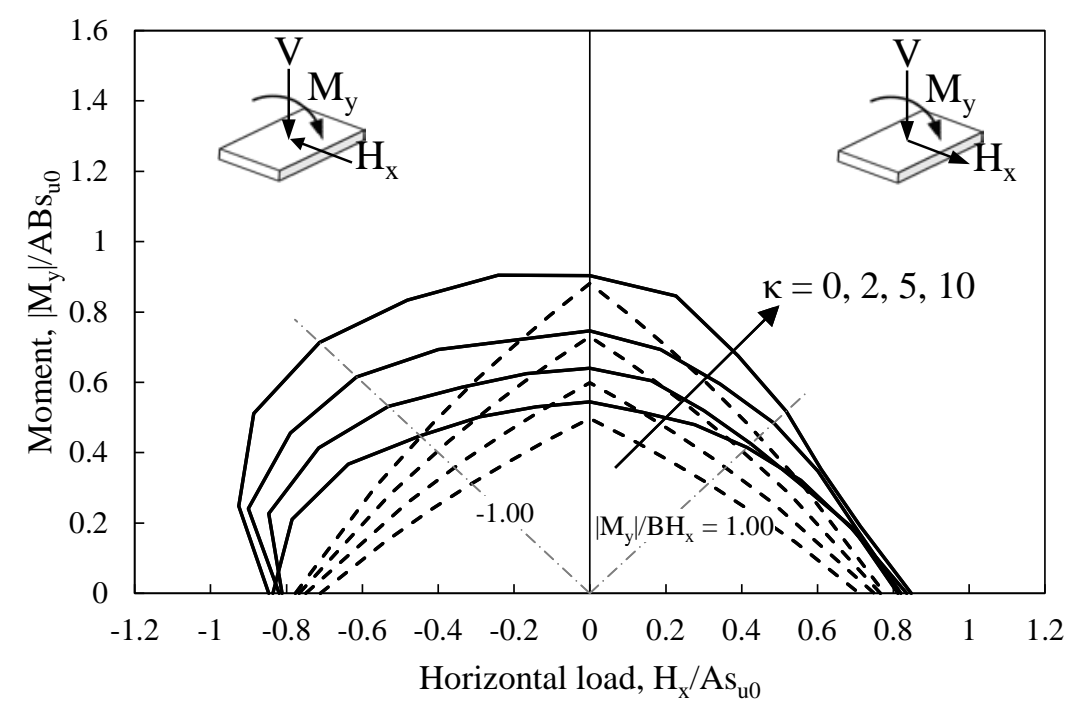

405

$406 \quad$ c) $\mathrm{v}=0.75$

407 Fig. 10. Failure envelopes for combined $V-H_{x}-M_{y}$ loading 


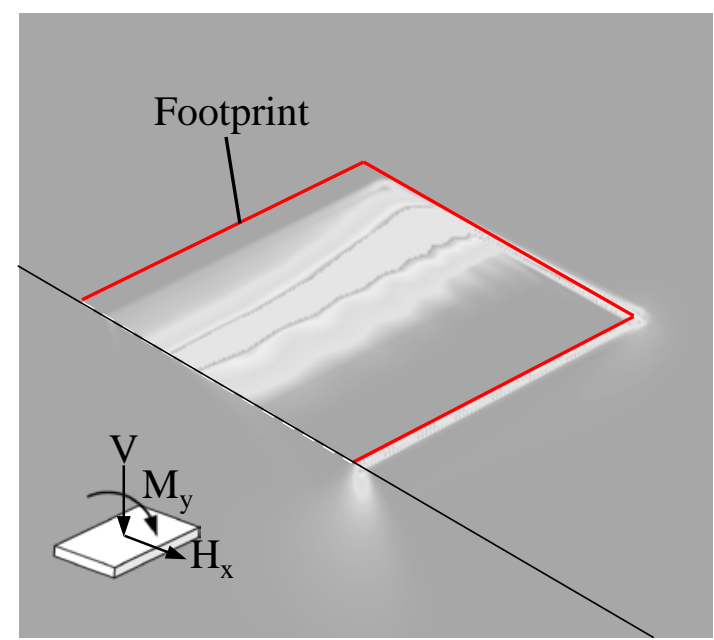

a) $\left|\mathrm{M}_{\mathrm{y}}\right| / \mathrm{BH}_{\mathrm{x}}=1.00$

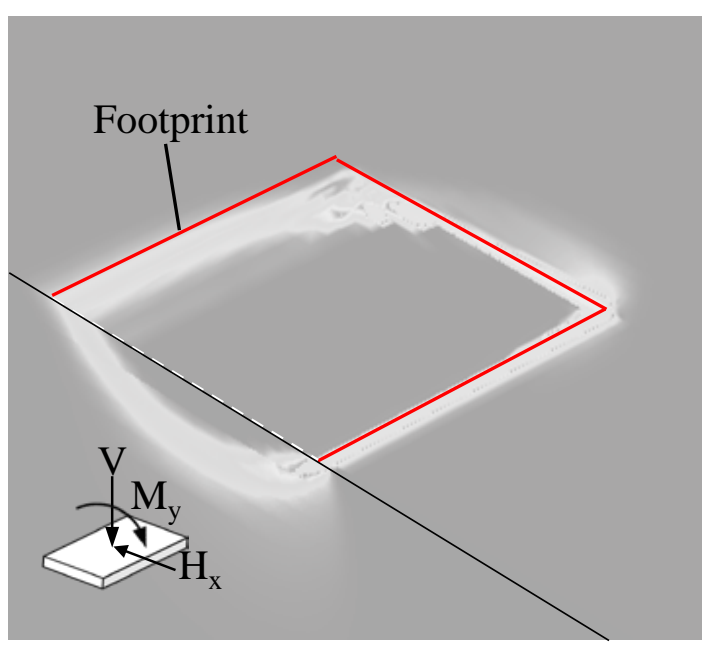

b) $\left|\mathrm{M}_{\mathrm{y}}\right| / \mathrm{BH}_{\mathrm{x}}=-1.00$

Fig. 11. Example of equivalent plastic strain in the soil for given load path $(v=0.5 ; \kappa=0)$

409

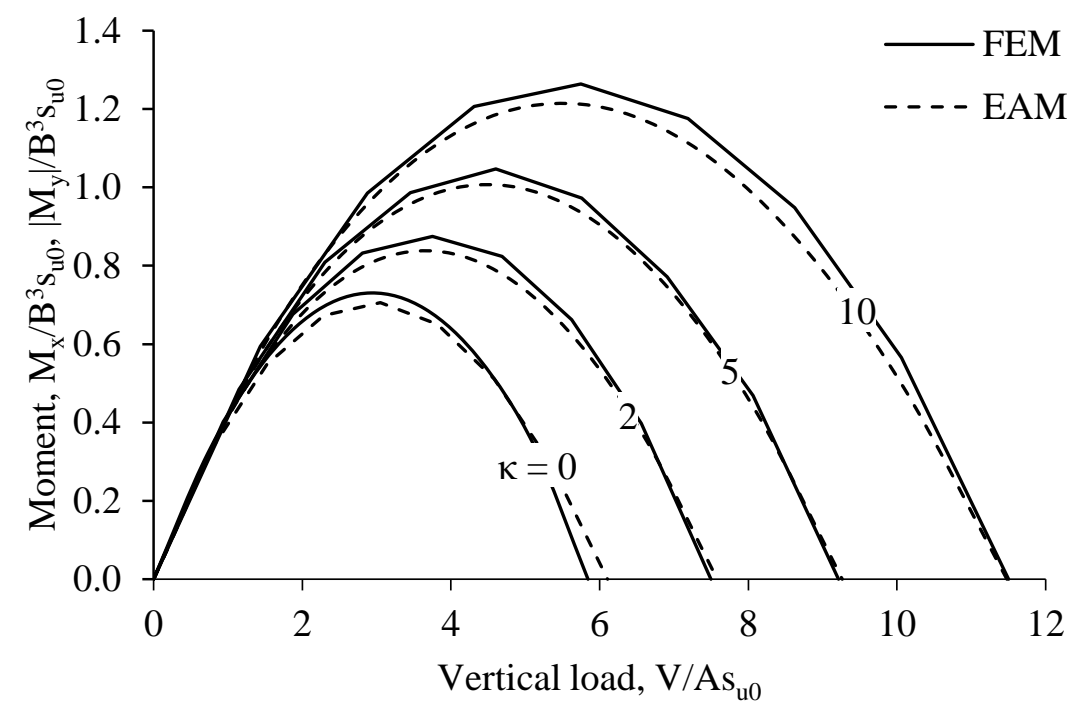

a) V-M capacity: one-way eccentricity 


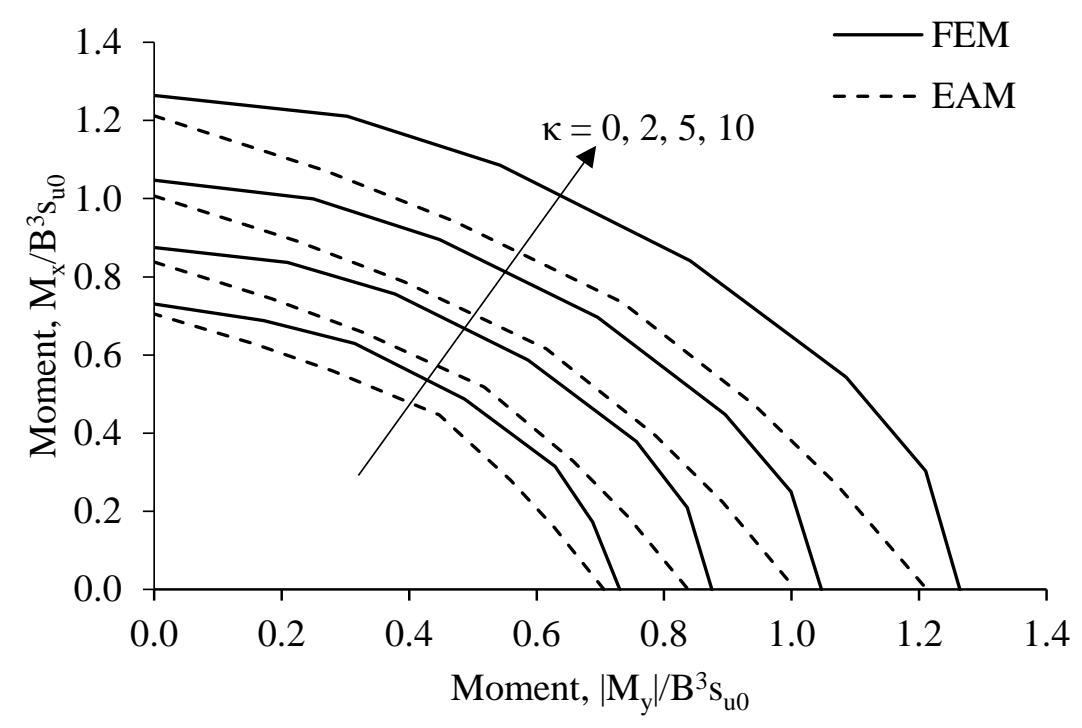

413 b) V-M capacity: two-way eccentricity $(\mathrm{v}=0.5)$

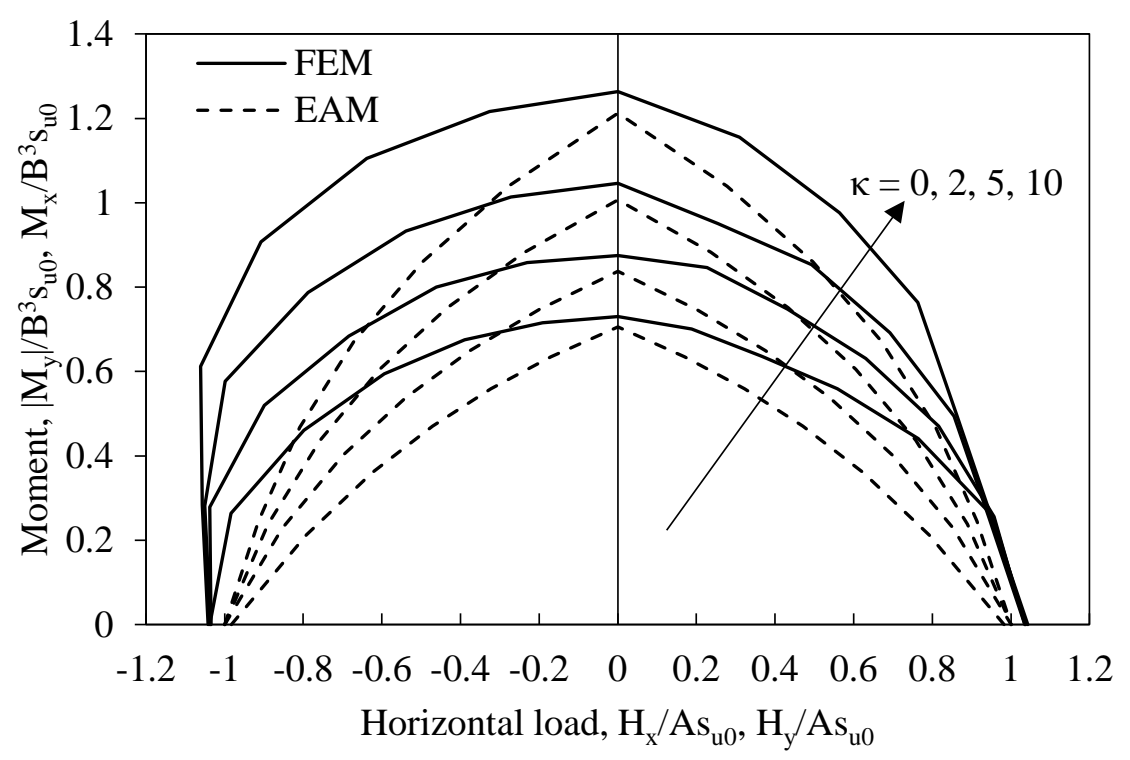

Horizontal load, $\mathrm{H}_{\mathrm{x}} / \mathrm{As}_{\mathrm{u} 0}, \mathrm{H}_{\mathrm{y}} / \mathrm{As}_{\mathrm{u} 0}$

415 c) $\mathrm{V}-\mathrm{H}-\mathrm{M}$ capacity $(\mathrm{v}=0.5)$

416 Fig. 12. Effectiveness of the EAM for square foundations and varying soil heterogeneity 